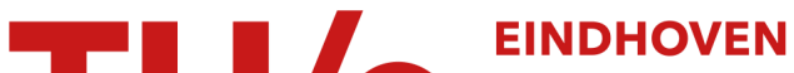 UNIVERSITY OF TECHNOLOGY
}

\section{Fatigue life prediction of hot riveted double covered butt joints}

\author{
Citation for published version (APA): \\ Maljaars, J., Leonetti, D., \& Maas, C. (2019). Fatigue life prediction of hot riveted double covered butt joints. \\ International Journal of Fatigue, 124, 99-112. https://doi.org/10.1016/j.ijfatigue.2019.03.002
}

\section{Document license: \\ TAVERNE}

DOI:

10.1016/j.ijfatigue.2019.03.002

Document status and date:

Published: 01/07/2019

\section{Document Version:}

Publisher's PDF, also known as Version of Record (includes final page, issue and volume numbers)

\section{Please check the document version of this publication:}

- A submitted manuscript is the version of the article upon submission and before peer-review. There can be important differences between the submitted version and the official published version of record. People interested in the research are advised to contact the author for the final version of the publication, or visit the $\mathrm{DOI}$ to the publisher's website.

- The final author version and the galley proof are versions of the publication after peer review.

- The final published version features the final layout of the paper including the volume, issue and page numbers.

Link to publication

\section{General rights}

Copyright and moral rights for the publications made accessible in the public portal are retained by the authors and/or other copyright owners and it is a condition of accessing publications that users recognise and abide by the legal requirements associated with these rights.

- Users may download and print one copy of any publication from the public portal for the purpose of private study or research.

- You may not further distribute the material or use it for any profit-making activity or commercial gain

- You may freely distribute the URL identifying the publication in the public portal.

If the publication is distributed under the terms of Article 25fa of the Dutch Copyright Act, indicated by the "Taverne" license above, please follow below link for the End User Agreement:

www.tue.nl/taverne

Take down policy

If you believe that this document breaches copyright please contact us at:

openaccess@tue.nl

providing details and we will investigate your claim. 


\title{
Fatigue life prediction of hot riveted double covered butt joints
}

\author{
Johan Maljaars ${ }^{\mathrm{a}, \mathrm{b}, *}$, Davide Leonetti ${ }^{\mathrm{a}}$, Carlo Maas ${ }^{\mathrm{a}, \mathrm{c}}$ \\ ${ }^{a}$ Eindhoven University of Technology, Department of the Built Environment, the Netherlands \\ ${ }^{\mathrm{b}}$ TNO, Department of Structural Reliability, the Netherlands \\ ${ }^{\mathrm{c}}$ Apcon, the Netherlands
}

\section{A R T I C L E I N F O}

\section{Keywords:}

Hot riveting

Low cycle fatigue

Notch stress

Stress intensity factor

ESED

\begin{abstract}
A B S T R A C T
Many existing steel bridges are constructed by using hot-driven steel rivets as fasteners. It is known that the fatigue strength of these joints depends on their geometry, since it affects the load transfer mechanism and, therefore, the severity of the stress concentration. Attempts have been taken in the past to provide the characteristic fatigue strength of riveted joints based on test results, i.e. to provide a detail classification. However, the limited number of experimental results per geometry and their large scatter jeopardises the accuracy of the classification, which has resulted into different classifications by different researchers. This paper presents a theoretical fatigue strength prediction model for hot riveted double covered butt joints. The model results agree very well with fatigue test data and the model provides a fundamental understanding of the empirical observations. The model reveals that the classification of joints as proposed in the past is inaccurate for many cases. As an example, the plate width over rivet diameter ratio and the surface finish have a much larger influence on the strength than what has always been considered, whereas the ultimate tensile strength of the plate material has limited influence.
\end{abstract}

\section{Introduction}

Hot-riveting was the main fastening technology for steel bridges up until halfway the previous century. In the hot-riveting process, a rivet is heated to approximately $1000^{\circ} \mathrm{C}$, driven in a drilled or punched hole, and then hammered, whereby a field head is formed [1]. The rivet contracts while cooling, thereby clamping the plates. Many of these bridges are still in service but were not designed for today's traffic intensity. The remaining fatigue life is therefore a critical aspect for these bridges.

Distinction is made between riveted joints in tension and shear joints, [2]. Whereas in tension riveted joints the rivets are loaded in tension, in the second type they are predominantly loaded by shear forces. The load in a shear riveted joint is transferred between the plates through a combination of frictional and bearing forces. If subjected to cyclic loading, fatigue cracks occasionally occur in the rivet, but predominantly they nucleate in one of the plates at the notch root [3], i.e. the location around the hole where stress concentration occurs. The theoretical stress concentration factor (SCF), i.e. the ratio between the theoretical notch stress and the stress applied to the gross section, $\sigma_{a p p}$, is used to quantify the severity of the stress state and is found to be inversely proportional to the fatigue strength. It depends on many aspects: (1) the friction coefficient, which is one of the parameters influencing the load transfer mechanism. If the load is considered to be transferred by a combination of frictional and bearing forces, the friction coefficient influences the maximum load that can be transferred through friction. By using the linear superposition principle, the SCF can be expressed as a linear combination of the SCF related to these two elementary loading modes. The surface finish applied on the plates varied between countries and in time. Tests in $[2,4]$ indicate that the average friction coefficient is approximately $\mu=0.5$ for sand or grit blasted steel plates, $\mu=0.3$ for clean mill scale and $\mu=0.06$ for plates coated with red lead paint. The coefficient of variation of the friction coefficient is approximately 0.1. (2) The rivet clamping force influences the friction resistance of the joint, because it contributes to the extent of the maximum force that can be transferred through friction. The clamping force depends on rivet length and riveting method and it varies from rivet to rivet. Measurements indicate that the average clamping force decreases and the standard deviation increases with decreasing rivet length, $[5,6]$. The lower average value is attributed to rivet head deformation, which is more important for short rivets. Hydraulic driven rivets generally have a larger and less scattered clamping force than rivets driven with a pneumatic hammer, [7]. Hammer driven rivets provide the largest scatter. (3) The type and configuration of the joint, e.g. single rivet double covered butt joints having larger bearing stress as compared to built-up beams. The ratio between the gross and

\footnotetext{
* Corresponding author at: Eindhoven University of Technology, Department of the Built Environment, Den Dolech 2, 5612 AZ Eindhoven, the Netherlands.

E-mail address: johan.maljaars@tno.nl (J. Maljaars).
} 
the net section is obviously important in double covered butt joints, [8]. In addition, the number of rivet rows influences the SCF.

Debate exists on the influence of the type of material. Puddle iron, also called wrought iron, and mild steels were both used in bridge construction up to approximately the beginning of the 20th century. Less old riveted bridges are composed of mild steels. The crack growth rate and fracture toughness of puddle iron as a base material differs from that of mild steels, [9]. Comparing the strain-life curves for puddle iron in [10] with the relationships for steels in [11], it appears that the life to crack initiation is also different, especially for large stress (or strain) ranges. The recommendation [12] provides a higher fatigue strength for riveted joints in steels than for wrought iron. On the contrary, [7] concludes there is no distinct influence of the material type. A similar debate exists on the influence of the stress ratio, i.e. the ratio between the minimum and maximum applied stress of the cycle: Based on regression of test data, [3] concluded that the stress ratio has no distinct influence on the fatigue strength, and this conclusion was adopted in modern recommendations such as [13], whereas other sources provide a significant dependency between stress ratio and fatigue strength, e.g. $[7,12]$. Rivet holes were produced by drilling or punching, the latter method often followed by rimming the hole. The surface is expected to be smooth in both cases. Tests in [14] indicate that the hole forming method - i.e. drilling or punching - has no distinct influence on the fatigue strength, provided that the rivet is clamping the plates.

Guidelines $[7,12,13,15]$ give characteristic fatigue strength values of hot riveted joints, usually related to the 5 th percentile of the fatigue life at 2 million cycles. The recommended values vary widely. The characteristic fatigue strength in guidelines issued before 2010 was often provided independently of the type of riveted joint and stress ratio and equal to $71 \mathrm{MPa}[13,15]$. This fatigue strength was backed by statistical evaluation of tests in $[3,16]$. In 2010, Taras and Greiner [7] argued that the fatigue strength should be provided as a function of the joint type and stress ratio. From that time onwards, the characteristic fatigue strength provided in guidelines for hot riveted double covered butt joints ranged between $80 \mathrm{MPa}$ or $90 \mathrm{MPa}$ [7], and $122 \mathrm{MPa}$ [12] for an applied stress ratio of $R_{\text {app }}=0$. The characteristic fatigue strength evaluated from tests on the same type of joint in puddle iron ranges between $52 \mathrm{MPa}$ [17] and $107 \mathrm{MPa}$ [18]. All of these fatigue strength values are based on regression of tests and are thus purely phenomenological. The large variation in possible geometries and load conditions of riveted double covered butt joints on the one hand, and the scattered experimental results with small sample size per series on the other hand - many series consist of maximum 4 tests only - complicate the evaluation of the test results. This is probably the reason for the large variation in the characteristic fatigue strength provided by previous research and adopted in the aforementioned recommendations.

Fatigue life prediction models have been applied before for the assessment of riveted joints. Most studies considered one or both of the following predictions: (1) Prediction of the fatigue initiation life. The SCF required for this prediction is usually determined from a finite element (FE) model of the riveted joint geometry. (2) Prediction of the fatigue propagation life. The stress intensity factor (SIF) is determined from a FE model of the riveted joint geometry. A number of studies considered riveted built up beam details. Al-Emrani and Kliger [19] carried out detailed FE analyses for the SCFs of built up beams. Correia and De Jesus [20] considered the SIF and crack growth in a built up beam. Imam and Righiniotis [21] performed fatigue life prediction on a beam to cross girder joint using a refined FE model and the theory of critical distances to perform the fatigue life prediction. The aspects dominating the fatigue performance mentioned earlier, such as the clamping force and friction between the plates, were considered in these studies. In addition to these details, lap riveted joints have been analysed. The elastic-plastic stress at the notch was determined with an FE model and was used to estimate the fatigue life of lap joints in $[22,23]$, without modelling the clamping force provided by the rivets.
Marmo [24] modelled riveted lap joints, including clamping and friction, and used this to predict failure modes in monotonic loading. The study shows that a dense mesh is required if contact and non-linear material behaviour are combined in the FE model. A comprehensive study into crack initiation and growth of single sided lap joints and double covered butt joints was performed by de Jesus, Correia, and others, [25,26]. A good agreement was obtained between the model prediction and the results of fatigue tests. In most of these studies, a linear elastic material model is used for the FE models and the resulting theoretical notch stresses are translated into cyclic stresses using theoretical models and correlations, e.g. the Neuber rule.

This paper provides a prediction model for the fatigue strength of hot riveted double cover butt joints using a two-stage fatigue model, consisting of: (1) A fatigue initiation life model based on the BasquinManson-Coffin relationship, incorporating the Morrow mean stress correction rule. (2) A fatigue propagation life model based on Paris' equation. Similarly to the other studies presented in the literature, the cyclic mean stress and strain amplitude required for the fatigue life estimation are determined from a FE model of the riveted joint geometry. However, differently from the other models, the unloading stage is considered here: The stresses and the strains for fatigue life prediction are evaluated from the FE model for both the loading and the unloading phases of the stress cycles, regardless of the minimum value of the applied load. This allows accounting for non-linear effects such as contact location and frictional forces. The presence of frictional forces causes that a residual stress remains after unloading, which influences the stress range and stress ratio. Thus, a realistic prediction requires the evaluation of the residual stress after unloading has occurred.

A second difference is that most other studies derived and applied SCFs that depend on friction coefficient, clamping force, and geometry. In addition to these aspects, Section 4 of this paper demonstrates that the ratios between notch stress and applied stress also depend on the applied stress itself, i.e. there are no fixed SCFs, because the fraction of the load transferred though bearing (and through friction) depends on the applied load. A similar observation applies to the SIF. Using fixed SCFs and ignoring the residual stress after unloading can be a reasonable approach, but only if the applied load is large as compared to the clamping force.

Finally, the model is applied to a large range of geometries of hot riveted double covered butt joints. This enables to draw conclusions regarding the importance of the different parameters that influence the fatigue strength. The combination of tests and prediction model makes the fatigue strength prediction less ambiguous and makes it easier to retrieve trends and influence parameters. The paper evaluates the recommended fatigue strength values based on a combination of tests and model and provides a more accurate prediction framework for fatigue of hot riveted double covered butt joints as compared to the current state of the art.

\section{Fatigue life prediction model}

The crack initiation model applied in this paper is elaborated in [27]. This section provides a summary of the model, including the equations, the material parameters, and their sources. Fatigue crack initiation is modelled using the Basquin-Manson Coffin strain-life relationship [28] with mean stress correction according to Morrow [29]:

$e_{a}=\frac{s_{f}-s_{m}}{E}\left(2 N_{i}\right)^{b^{b}}+e_{f}^{\prime}\left(2 N_{i}\right)^{c}$

where:

$e_{a}=$ cyclic strain amplitude caused by the load cycle

$s_{m}=$ average cyclic stress caused by the load cycle

$E=$ Youngs modulus

$N_{i}=$ number of cycles to crack initiation 
$s_{f}^{\prime}=$ material dependent constant in the stress amplitude versus life regime

$b^{\prime}=$ material dependent exponent in the stress amplitude versus life regime, corrected to account for surface roughness effect

$e_{f}^{\prime}=$ material dependent constant in the strain amplitude versus life regime

$c^{\prime}=$ material dependent exponent in the strain amplitude versus life regime

Eq. (1) covers the low- and the high-cycle fatigue regime, and it is widely used for strain-based fatigue life assessment. The values for the material dependent variables are provided later in this section. The Ramberg Osgood relationship [30] is used to estimate the cyclic stressstrain relation:

$e_{\max }=\frac{s_{\max }}{E}+\left(\frac{s_{\max }}{K^{\prime}}\right)^{1 / n^{\prime}}$

where:

$s_{\max }=$ cyclic stress at maximum applied load

$e_{\max }=$ cyclic strain at maximum applied load

$K^{\prime}=$ material cyclic strain hardening coefficient

$n^{\prime}=$ material cyclic strain hardening exponent

In agreement with [31], the cyclic strain hardening constant, $K^{\prime}$, and exponent, $n^{\prime}$, in Eq. (2) are approximated from the strain life variables:

$n^{\prime}=b / c$

$K^{\prime}=\frac{s_{f}^{\prime}}{\left(e_{f}^{\prime}\right)^{n^{\prime}}}$

The variable $b$ in Eq. (3) is solely depending on material, but variable $b^{\prime}$ in Eq. (1) also includes the influence of the surface roughness on fatigue crack initiation. Their relationship is determined in [32] based on evaluation of tests on plain material:

$b^{\prime}=b+\frac{\log _{10}\left(k_{a}\right)}{\log _{10}\left(2 N_{0}\right)}$

where:

$$
\begin{aligned}
& k_{a}=\text { factor for surface roughness } \\
& N_{O}=\text { constant amplitude fatigue limit for plain material. }
\end{aligned}
$$

The cyclic, elastic-plastic stress and strain at the notch are estimated from the theoretical fatigue notch stress, $\sigma^{\prime}$. The method used here for this estimation is the equivalent strain energy density (ESED) method [33], which assumes that the linear elastic strain energy is equal to the cyclic strain energy:

$\int_{0}^{\varepsilon} \sigma^{\prime} \mathrm{d} \varepsilon=\int_{0}^{e} s \mathrm{~d} e$

where:

$$
\begin{aligned}
& \varepsilon=\text { linear elastic strain } \\
& e=\text { cyclic strain } \\
& s=\text { cyclic stress }
\end{aligned}
$$

Substituting Eq. (2) into (6) and integrating it provides the following relationship between the theoretical fatigue notch stress at maximum applied load, $\sigma_{\max }^{\prime}$, and its cyclic equivalent, [33]:

$$
\frac{\sigma_{\max }^{\prime 2}}{2 E}=\frac{s_{\max }^{2}}{2 E}+\frac{s_{\max }}{n^{\prime}+1}\left(\frac{s_{\max }}{K^{\prime}}\right)^{1 / n^{\prime}}
$$

Similar to Eqs. (2) and (7), the following equations apply for the strain amplitude and the stress range, $[29,33]$ :

$e_{a}=\frac{\Delta s}{2 E}+\left(\frac{\Delta s}{2 K^{\prime}}\right)^{1 / n}$

$\frac{\left(\sigma_{\max }^{\prime}-\sigma_{\min }^{\prime}\right)^{2}}{2 E}=\frac{\Delta s^{2}}{2 E}+2 \frac{\Delta s}{n^{\prime}+1}\left(\frac{\Delta s}{2 K^{\prime}}\right)^{1 / n^{\prime}}$

where:

$\Delta s=$ cyclic stress range

$\sigma_{\min }^{\prime}=$ theoretical fatigue notch stress at minimum applied load

The average elastic-plastic stress of the cycle, $s_{m}$, follows from:

$s_{m}=s_{\max }-\frac{\Delta s}{2}$

The theoretical maximum and minimum fatigue notch stress accounts for the large stress gradient near the notch. It considers the support that the notch experiences from the surrounding, less strained material, which is not considered in a model with linear elastic material properties. The method described in [34] is adopted:

$\frac{\sigma_{\max }^{\prime}}{\sigma_{\max }}=\frac{\sigma_{\min }^{\prime}}{\sigma_{\min }}= \begin{cases}\frac{1}{1+G \cdot 10^{-\left(a_{G}-0.5+f_{u} / b_{G}\right)}} & \text { if } G<0.1 \\ \frac{1}{1+\sqrt{G} \cdot 10^{-\left(a_{G}+f_{u} / b_{G}\right)}} & \text { if } 0.1 \leq G \leq 1\end{cases}$

$G=\frac{\left(\sigma_{\max }-\sigma_{\min }\right)-\left(\sigma_{\delta, \max }-\sigma_{\delta, \min }\right)}{\left(\sigma_{\max }-\sigma_{\min }\right) \cdot \delta / m m}$

where:

$\sigma_{\max }=$ theoretical maximum stress at the notch from a model with linear elastic material properties

$\sigma_{\delta \text {, max }}=$ theoretical maximum stress at a distance $\delta$ away from the notch from a model with linear elastic material properties

$\sigma_{\min }=$ theoretical minimum stress at the notch from a model with linear elastic material properties

$\sigma_{\delta \text {, min }}=$ theoretical minimum stress at a distance $\delta$ away from the notch from a model with linear elastic material properties

$f_{u}=$ tensile strength

$a_{G}$ and $b_{G}=$ material variables

Theoretical stresses $\sigma_{\max }, \sigma_{\delta \text {, max }}, \sigma_{\min }$ and $\sigma_{\delta \text {,min }}$ are obtained from the FE model, where $\sigma_{\delta, \max }$ and $\sigma_{\delta \text {, min }}$ are determined one element away from the notch, from which also distance $\delta$ follows. Section 3 of this paper shows that the theoretical stress from a model with linear elastic material properties highly depends on the geometry and loading case, but the stress gradient varies to a lesser extent. The average ratio $\frac{\sigma_{\max }}{\sigma_{\max }}$ is 0.88 for the geometries considered in Sections 3 and 4 .

Hence, for each geometry and loading condition the FE model is used to determine the theoretical stress at the notch root at the maximum and the minimum applied load, $\sigma_{\max }$ and $\sigma_{\min }$ and the theoretical stress $\sigma_{\delta, \max }$ and $\sigma_{\delta, \min }$ evaluated one element away from the notch at maximum and minimum applied load, respectively. The theoretical fatigue notch stresses $\sigma_{\max }^{\prime}$ and $\sigma_{\min }^{\prime}$, determined using Eqs. (11) and (12), are applied in Eqs. (7) and (9) to obtain $s_{\max }$ and $\Delta s$. Subsequently, $e_{a}$ and $s_{m}$ follow from Eqs. (8) and (10). The number of cycles to crack initiation, $N_{i}$, can be then determined using Eq. (1).

The theory of linear elastic fracture mechanics is applied to model crack propagation. Paris' equation [35] is applied:

$\frac{\mathrm{d} a}{\mathrm{~d} N_{p}}=A\left(K_{\max }-K_{\min }\right)^{p}$

where:

$a=$ crack size 


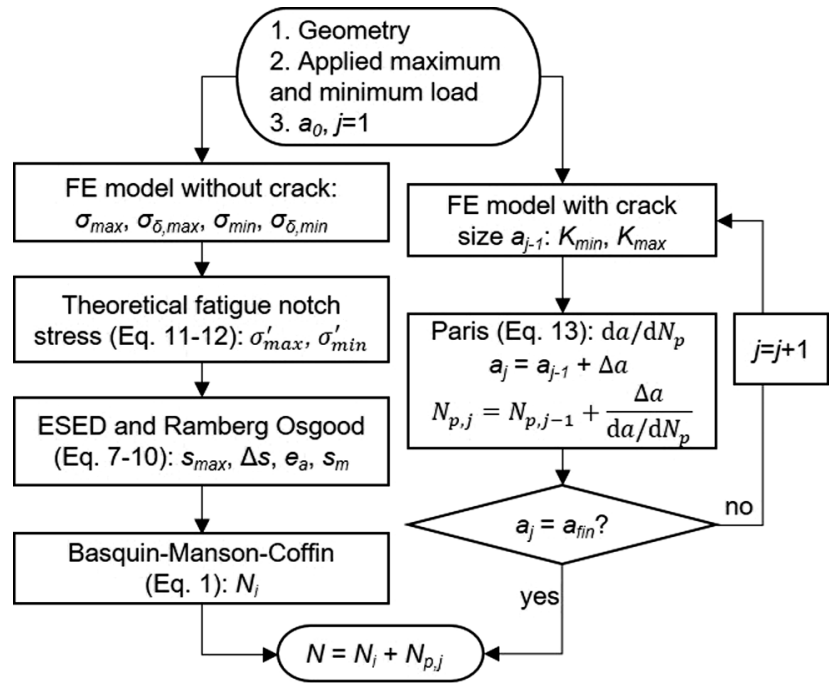

Fig. 1. Flow chart of the fatigue life prediction.

$N_{p}=$ number of cycles for crack propagation

$K_{\max }=$ SIF at maximum applied load

$K_{\min }=$ SIF at minimum applied load

$A=$ material crack growth constant

$p=$ material crack growth exponent

The SIFs are obtained from the FE model and a straightforward numerical solving algorithm for the integral of Eq. (13) is used to determine the number of cycles, $N_{p}$, to propagate a crack from an initial size, $a_{O}$, to a final size, $a_{\text {fin }}$. The number of cycles to failure, $N$, is the summation of the initiation and propagation lives, $N_{i}+N_{p}$. Fig. 1 provides the flowchart of the fatigue life prediction.

Table 1 provides the material variables and their relations and values. Average values for the material variables in the prediction model are taken from experimental data on plain material in literature. For steel, correlations between the material variables and the Brinell hardness $H_{b}$, provided in [36] are used. The values measured in [10] are applied for puddle iron. The surface roughness factor, $k_{a}$, is taken from [32] for a machined surface, because that surface condition is considered representative for drilled or rimmed holes. The crack growth constant, $A$, depends on the stress ratio at the notch, $R$. Values for variables $A$ and $p$ are taken from Gallegos Mayorga et al. [37] for puddle iron and from BS 7910 [38] for steels, because tests on old steels in [39-41] indicate that the crack growth rate agrees reasonable with the values in [38].

\section{Geometry and finite element model}

Joints with one and two rivets per side and with two cover plates according to Fig. 2 are considered, with the following ranges of dimension: $0.1 \leq r / w \leq 0.53,0.8 \leq h / d \leq 3.2,0 \leq a / w \leq 0.65, t_{c}>t$, $0 \leq g / r \leq 0.01$, where $g$ is the difference between the hole radius and the rivet radius. The model considers fatigue of the central (i.e. interrupted) plate with cracks emanating from the rivet hole at the net section. An isotropic linear elastic material model is used with $E=2 \cdot 10^{5} \mathrm{MPa}$ and $\nu=0.3$. Friction is considered at all contacting surfaces - between the plates, between the cover plate and the rivet head and between the plates and the rivet shaft. The friction coefficient applied in the simulations ranges between $0<\mu \leq 0.5$.

The analyses are performed with the FE software ANSYS 17.2 using 20 node hexahedral elements with reduced integration scheme (type SOLID186). The SIF is determined from a model including a two-sided through-thickness crack with a straight front using the contour integration method [42]. The 3rd contour is used to extrapolate the solution. One eighth of the geometry is modelled, indicated with the hashed area in Fig. 2, applying symmetry boundary conditions at the symmetry faces. Consequently, the models including cracks assume cracks at both sides of the joint. The SIF of this symmetrical case is compared to the SIF of a case containing cracks at one rivet hole. A model is made for this purpose using two symmetry axes, both parallel to the load direction, so that the model contains a quarter of the geometry. The difference in SIF between these two models is $1 \%$ only. Because of this small difference, the model results can be considered applicable to both cases.

The rivet clamping force $F_{c}$ is applied by temperature-induced contraction. An isotropic linear expansion coefficient is therefore provided to the rivets and a temperature drop is applied, causing the rivets to contract, before the external load $F$ is applied. The temperature drop is selected by trial and error as to obtain the desired clamping force. A small gap $g$ between the rivet and the plates results because of the thermal contraction and this is in line with experimental observations in [43]. Some simulations are repeated with a different, intended gap to determine the influence. The load $F$ is subsequently applied as a uniform stress at the end of the central plate. Frictional contact is modelled

Table 1

Average values for material variables in the crack initiation model.

\begin{tabular}{|c|c|c|c|}
\hline Description & Symbol & Value & Source \\
\hline Brinell hardness & $H_{b}$ & $f_{u} /(345 \mathrm{MPa})$ & \\
\hline Exponent in the stress amplitude versus life regime & $b$ & -0.09 & [11] \\
\hline Exponent in the strain amplitude versus life regime & $c$ & $\begin{array}{l}-0.56 \text { for steel } \\
-0.74 \text { for puddle iron }\end{array}$ & $\begin{array}{l}{[11]} \\
{[10]}\end{array}$ \\
\hline Constant in the stress amplitude versus life regime & $s_{f}^{\prime}$ & $\begin{array}{l}\left(4.25 H_{b}+225\right) \mathrm{MPa} \text { for steel } \\
627 \mathrm{MPa} \text { for puddle iron }\end{array}$ & $\begin{array}{l}{[36]} \\
{[10]}\end{array}$ \\
\hline Constant in the strain hardening versus life regime & $e_{f}^{\prime}$ & $\frac{0.32 H_{b}^{2}-487 H_{b}+191000}{E / \mathrm{MPa}}$ for steel & [36] \\
\hline Young's modulus & $E$ & $\begin{array}{l}0.39 \text { for puddle iron } \\
2 \cdot 10^{6} \mathrm{MPa}\end{array}$ & {$[10]$} \\
\hline Constant amplitude fatigue limit for plain material & $N_{O}$ & $10^{6}$ & [34] \\
\hline Surface roughness factor for machined surface & $k_{a}$ & $4.51\left(\frac{f_{u}}{\mathrm{MPa}}\right)^{-0.265}$ & [32] \\
\hline Stress gradient constant & $a_{G}$ & 0.5 & [34] \\
\hline Stress gradient constant accounting for material strength & $b_{G}$ & $2700 \mathrm{MPa}$ & [34] \\
\hline Crack growth exponent & $p$ & $\begin{array}{l}2.88 \text { for steels }{ }^{\mathrm{a}} \\
5 \text { for puddle iron }\end{array}$ & $\begin{array}{l}{[38]} \\
{[37]}\end{array}$ \\
\hline Crack growth constant & $A$ & $\begin{array}{l}3.9 \cdot 10^{-13} \text { for steels }{ }^{\mathrm{a}} \\
\frac{10^{-18}}{(1-R)} \text { for puddle iron }\end{array}$ & {$[38]$} \\
\hline
\end{tabular}

${ }^{\text {a }}$ Values apply for $R<0.5$ and $\Delta K>360 \mathrm{~N} / \mathrm{mm}^{3 / 2}$. 


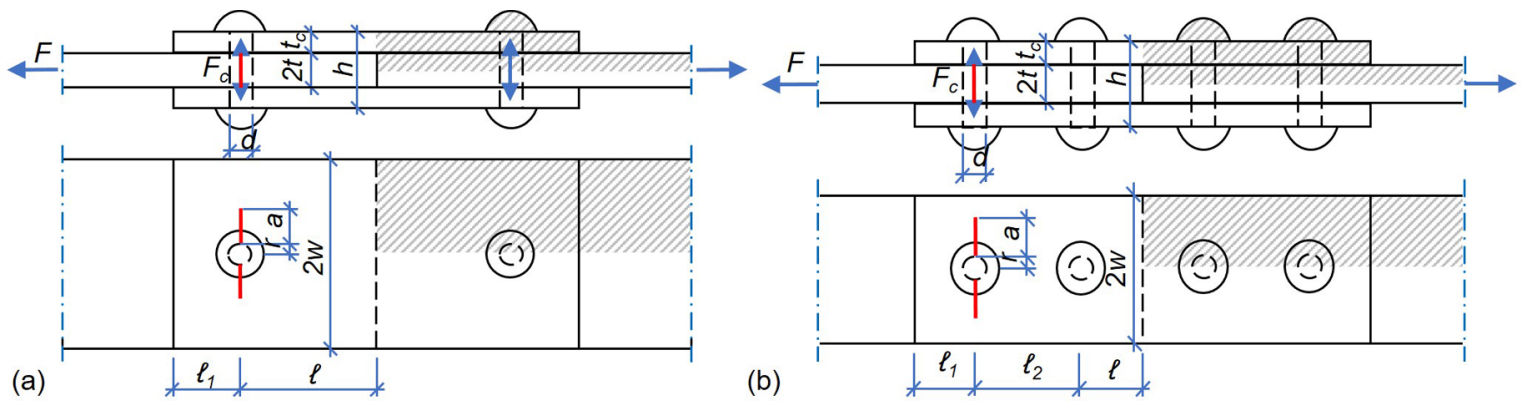

Fig. 2. Considered geometries of hot riveted double covered butt joints: (a) Model with one rivet per side; (b) Model with two rivets per side.

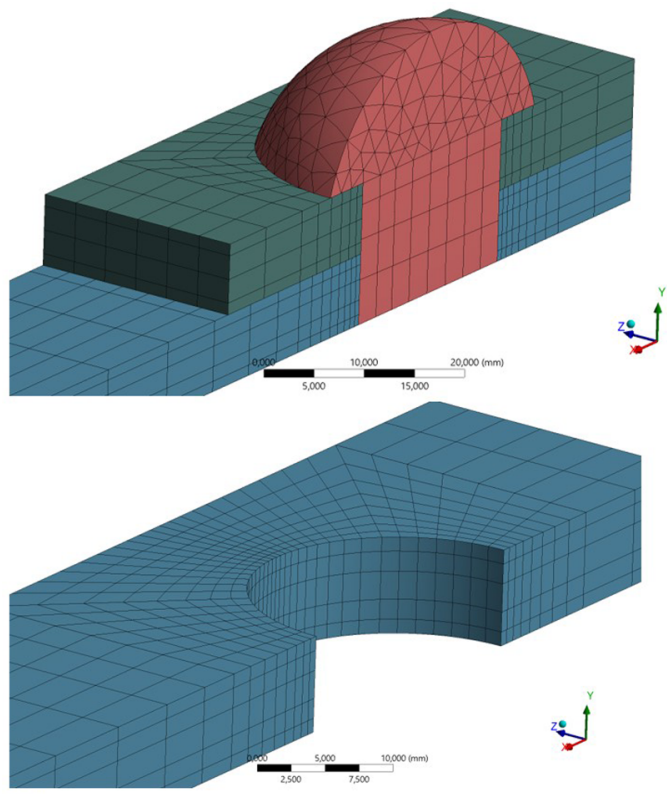

(a)

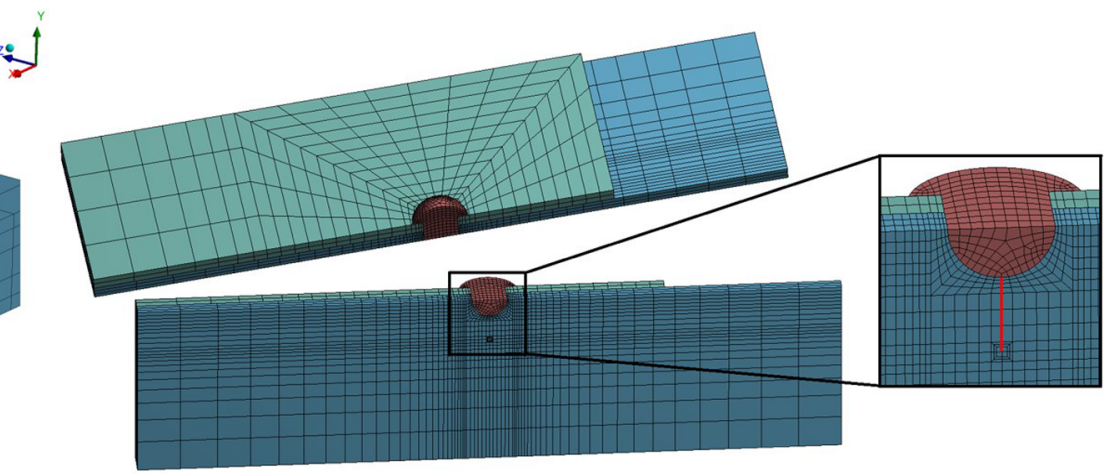

(b)

Fig. 3. Mesh of the FE models: (a) Model for SCF with $r / w=0.53$; (b) Model for SIF with $r / w=0.1$.

with a Coulomb friction model using the augmented Lagrange method for contact interaction, which penalizes penetration of bodies and requires the selection of a normal penalty stiffness factor (FKN) and a normal tolerance penetration factor (FTOLN), [44]. Both parameters influence the accuracy and convergence of the solution and their optimum values are problem-dependent. In addition, FTOLN is related to the mesh size. The default value FTOLN $=0.1$ is used in this study and the mesh size and FKN are selected with a sensitivity study in such a way, that the elastic peak stress and the SIF deviate with maximum $2 \%$ for a two times smaller element size or a two times larger FKN factor. Examples of the selected mesh are displayed in Fig. 3 and the FKN factor applied in most simulations is equal to 1 and in some simulations 10 or even 50.

The models are validated by comparing the results with the following reference cases in literature:

1. SCF of a plate with finite width and a centred hole. Results are compared with [45].

2. Same case but with pin loading at the hole with relative gap $g /$ $d=0.007$ and $g / d=0.013$, compared with [45].

3. SIF of a plate with a crack emanating from a hole, compared with [46].

4. Same case but with pin loading at the hole, compared with [47].

5. SIF of a double covered butt joint with a single rivet per side including clamping and friction for a geometry with $w=22.5 \mathrm{~mm}$, $r=12 \mathrm{~mm}, t=8 \mathrm{~mm}, h=32 \mathrm{~mm}$, compared with [25].
The SCF and SIF vary over the thickness according to the current model, with maximum values (at the plate centre) up to $20 \%$ larger as compared to the average. The average values over thickness are compared with the two-dimensional geometries considered in literature. The differences with the solutions for cases 1 up to 4 are approximately $1 \%$. The SIF in [25] was obtained using the energy release rate (VCCT technique) and a model consisting of elements with a full integration scheme. The applied load for which the SIF was derived, is not provided in [25]. In order to compare results, a large stress is applied to the model in the current study, so that (almost) the entire load is transferred through bearing, yielding an upper bound for the SIF. The SIF obtained in this way was maximum $5 \%$ and $10 \%$ larger for crack sizes $a=8 \mathrm{~mm}$ and $a=1 \mathrm{~mm}$, respectively, as compared to [25].

\section{Notch stress and stress intensity factors}

This section presents some of the findings of the study into SCF and SIF, in order to provide the insights required for understanding the trends in the fatigue strength that are presented later in this paper. The cover plate thickness is set equal to half the thickness of the main plate thickness, $t_{c}=t$, in the cases presented in this section.

A rivet tension force $F_{c}$ arises for any applied load $F$ (i.e. $F_{c}>0 \forall$ $F<>0$ ), even if the initial clamping force $F_{c o}=0$. This is due to prying of the rivet head because of rivet bending, Fig. 4a. Fig. $4 \mathrm{~b}$ gives the trend of the force that develops in the rivet as a function of the applied tensile load for an initial clamping force $F_{c o}>0$, demonstrated 


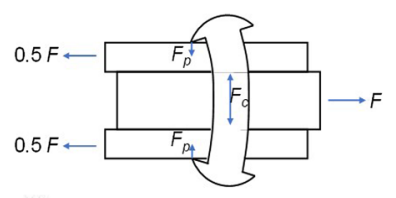

(a)

(b)

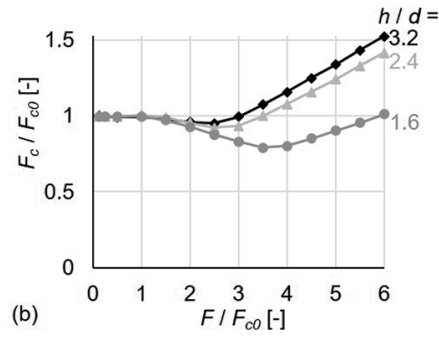

Fig. 4. Rivet tension force $F_{c}$ as a function of the applied load $F$ and the initial clamping force $F_{c o}$ : (a) Principle of prying; (b) Rivet tension force for a joint with one rivet, $r / w=0.2, \mu=0.5, \sigma_{c o}=100 \mathrm{MPa}$.

here for an initial clamping stress in the rivet of $\sigma_{c o}=100 \mathrm{MPa}$. The lateral contraction of the plates results into an initial reduction of $F_{c}$. At larger applied load, the rivet tension force increases due to prying. (Note that the figure is valid only up to yielding of rivet or plate.) This effect has been demonstrated for bolts in [48] but appears present also for rivets despite the smaller gap between the rivet shank and the hole. The prying effect reduces for increasing initial clamping force and it is smaller in case of short rivets.

Fig. 5 gives the SCF, $K_{t}$, for joints with one rivet in which an initial clamping force is not applied $\left(F_{c o}=0\right)$. This case is referred to as pin loading. The SCF is defined using the gross cross-section, i.e.

$K_{t}=\frac{\sigma}{\sigma_{a p p}}$

As a reference, the figure also provides the SCF of a single plate with a hole and a plate with a hole filling but unloaded pin (grey curves). This case is referred to as bypass loading. In line with earlier research, [45], the SCF for bypass loading increases with decreasing ratio $r / w$, i.e. the net section effect. This is not the case for pin loading, where an increasing pin load counterbalances the net section effect. The minimum value of $K_{t}$ for pin loading is obtained at $r / w=0.35$ in case of a small clearance. Interestingly, applying friction gives a higher SCF, which is attributed to friction stresses developing between the rivet shank and the hole surface.

The application of the clamping force in the FE model $\left(F_{c o}>0\right)$ results in an initial compression hoop stress at the hole edge, $\sigma_{0}$. Because the stress range is relevant for fatigue, a modified SCF, $K_{t}^{*}$, is defined where the initial stress state is subtracted from the notch stress, $\sigma$, at the applied average stress over the plate, $\sigma_{a p p}$ :

$K_{t}^{*}=\frac{\sigma-\sigma_{0}}{\sigma_{a p p}}$

Fig. 6a provides the modified SCF of a joint with a single, clamped rivet. The applied load is provided relative to the theoretical slip load:

$F_{\text {slip }}=n_{f} \mu F_{c 0}$

where the number of friction planes $n_{f}=2$. The figure shows the large

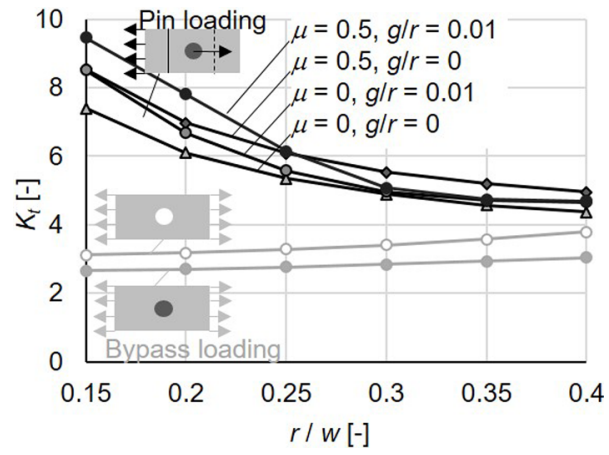

Fig. 5. Stress concentration factor, $K_{t}$, for cases without clamping force. influence of the applied load level on the SCF, which is caused by the fact that the applied load $F$ is transferred through a combination of friction and bearing. The bearing ratio is defined as:

$\beta=\max \left(\frac{F-F_{\text {slip }}}{F}, 0\right)$

Ref. [45] provides parametric expressions for the SCF of the cases bypass loading and pin loading:

$$
\begin{aligned}
K_{t, \text { byp }} & =\frac{2}{1-\frac{r}{w}}+0.284-0.6\left(1-\frac{r}{w}\right)+1.32\left(1-\frac{r}{w}\right)^{2} \\
K_{t, \text { pin }} & =\frac{1}{1-\frac{r}{w}}\left[12.882-52.714 \frac{r}{w}+89.762\left(\frac{r}{w}\right)^{2}-51.667\left(\frac{r}{w}\right)^{3}\right] \text { for } 0.2 \\
& \leq \frac{r}{w} \leq 0.75
\end{aligned}
$$

Combining these two expressions, the modified SCF of a riveted joint with clamping force can be approximated. Assuming a linear transition between pure friction and pure bearing, the SCF is written as:

$K_{t}=\beta K_{t, p i n}+(1-\beta) K_{t, f r i c}$

We have approximated $K_{t, \text { fric }}$ by considering the following theoretical model: A compression cone centred at the rivet hole is assumed to develop in the plates at $\beta=0$. Consequently, $50 \%$ of the frictional force is transferred in front of the hole and is not contributing to the stress concentration at the hole, and the other $50 \%$ is transferred behind the hole, and it is assumed to contribute to the stress concentration in the same manner as bypass loading. At a bearing ratio $\beta=1$, the prying effect causes that the contact predominantly establishes behind the rivet hole, resulting in a SCF at the hole corresponding to pin loading. A linear transition is assumed between these extreme cases:

$K_{t}=\left(2 \beta-\beta^{2}\right) K_{t, p i n}+0.5(1-\beta)^{2} K_{t, b y p}$

The dashed curve in Fig. 6a represent the expression. It agrees well with the simulations and this holds in general for single rivet cases with a high friction coefficient. For the case of two rivets, however, the bearing ratio cannot be obtained from a single equation because, the fraction of the load taken by each rivet is unknown on beforehand and depends on the ratio $r / l_{2}$, see Fig. 2 for the explanation of symbols. Fig. $6 \mathrm{~b}$ gives the modified SCF of three joints with various friction coefficients. The figure shows that the SCF is extremely sensitive to the ratio $r / w$. A negative correlation between friction coefficient and SCF occurs for low applied stress levels but a positive correlation is demonstrated for high applied stress. The latter is attributed to the fact that the SCF for pin loading is higher if frictional stresses arise between the rivet shank and the rivet hole, which can be addressed as a secondary effect that becomes dominant only at relatively high applied loads. Fig. $6 \mathrm{c}$ demonstrates that SCF is insensitive to the clamping force and friction coefficient at high stress ranges, where pin loading is dominant, but sensitive to these aspects at low stress ranges.

Full load cycles are considered hereafter. In the ideal case in which the frictional resistance is uniformly distributed and the load cycle is such that the maximum load exceeds the slip resistance given by Eq. (16), the stress state in the joint does not return to its original value after unloading because of the remaining frictional force. The FE model demonstrates that the real situation is more complex. The frictional resistance is not uniformly distributed between the plates, even if the coefficient of friction is, due to the uneven distribution of the normal contact pressure. The local action of the clamping force and the nonuniform lateral contraction in the thickness direction due to the Poisson effect are responsible for this. As a result, a residual stress state remains around the notch after unloading. The principle is shown in Fig. 7a, where the top graph gives the applied load and the bottom graph gives the resulting notch stress. The notch stress range of the 1 st semi cycle $\Delta \sigma_{1}$ may therefore differ from that of the subsequent cycles $\Delta \sigma_{2}$ and the 

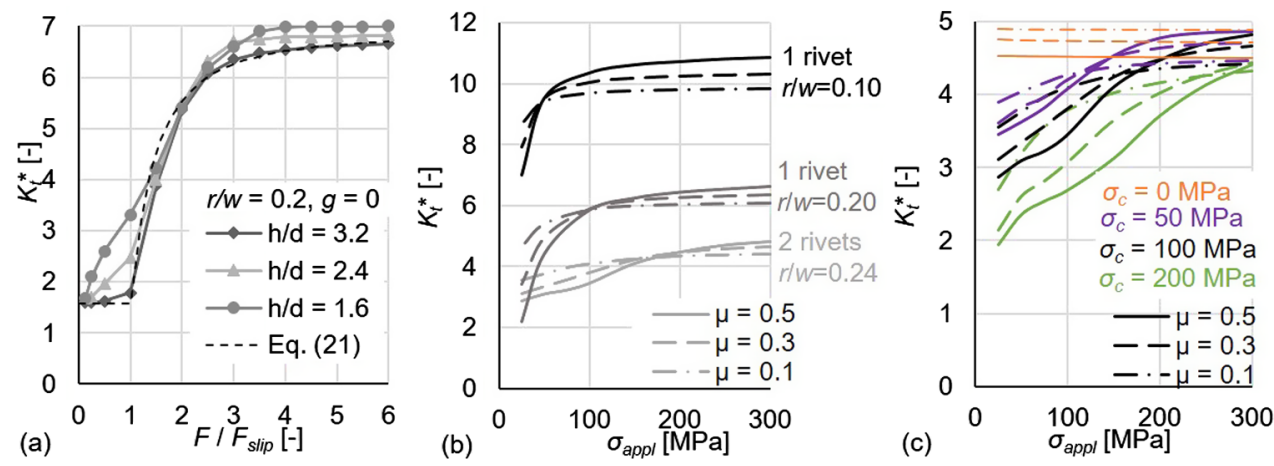

Fig. 6. Modified stress concentration factors, $K_{t}^{*}$ : (a) Modified SCF for a model with 1 rivet, $r / w=0.2, \mu=0.5, \sigma_{c o}=100$ MPa; (b) Modified SCF for models with 1 and 2 rivets and $\sigma_{c o}=100 \mathrm{MPa}$; (c) Modified SCF for a model with 2 rivets, $r / w=0.24$.

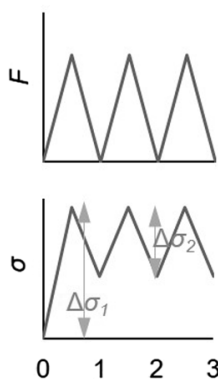

(a) load cycles $[-]$

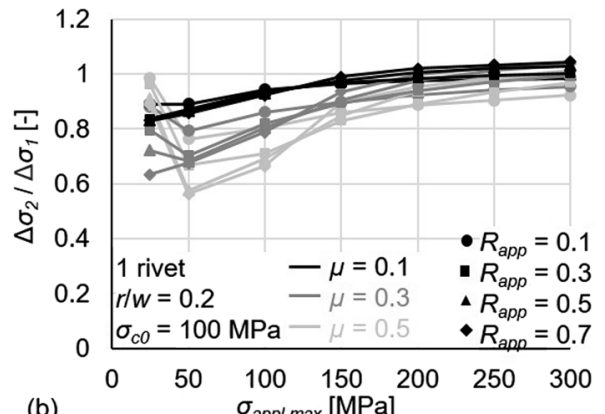

(b)

Fig. 7. Notch stress in case of cyclic loading: (a) Concept of the difference between first and following cycles; (b) Stress range ratio for a joint with one rivet.

same counts for the stress ratio, $R$. The friction coefficient may increase because of alternating slip, [49], but the friction coefficient used in this study, taken from [2], may already have taken this aspect into account. In the current study, a constant friction coefficient is therefore assumed. As an example, Fig. $7 \mathrm{~b}$ provides the ratio $\Delta \sigma_{2} / \Delta \sigma_{1}$ for a joint with certain geometry. The total applied load is transferred through friction for a combination of a high friction coefficient and clamping stress, and a low applied maximum stress, $\sigma_{a p p \text {,max }}$. In this case, the specimen returns to its original state when unloaded and thus $\Delta \sigma_{1}=\Delta \sigma_{2}$. On the other hand, the fraction of the load transferred through friction is negligible in case of a low friction coefficient combined with a high applied maximum stress, implying that, again, $\Delta \sigma_{1} \approx \Delta \sigma_{2}$. For intermediate combinations of friction and applied maximum stress, which are relevant for practical applications, the stress range of the second semi cycle is significantly lower as compared to that of the first semi cycle. This strongly non-linear behaviour suggests that the evaluation of the fatigue strength should be based on the simulation of the 2nd semi cycle. Additional cycles do not further alter the notch stress range and notch stress ratio. Therefore, the simulation of unloading is a prerequisite for realistically modelling the fatigue life.

The results of the models including cracks are presented via the geometric correction factor, $Y$, which is the ratio between the SIF of the considered geometry and the SIF of the theoretical case of an infinitely large plate with a central crack with size $2(a+r)$ :

$Y=\frac{K}{\sigma_{a p p} \sqrt{\pi(a+r)}}$

Fig. 8a provides the geometric correction factor as a function of the relative crack size for a joint with one rivet without a clamping force and with $r / w=0.1$. The figure demonstrates the large difference between bypass loading and pin loading and the minor influence of the friction coefficient for pin loading. This is due to the prying effect shown in Fig. 4a, which causes that the associated clamping occurs after the rivet and hence it has a marginal influence on the SIF. Fig. 8b and c give the geometric correction factor for a riveted joint with one and two rivets, respectively, both applying rivets with an initial clamping force $F_{c o}>0$. The effect of the clamping force is expressed through the theoretical bearing ratio, Eq. (17). The presented results are corrected for the SIF at zero applied load, $K_{o}$, in the same way as explained for the SCF:

$Y^{*}=\frac{K-K_{0}}{\sigma_{a p p} \sqrt{\mu(a+r)}}$

Fig. $8 \mathrm{~b}$ and $\mathrm{c}$ demonstrate that the bearing ratio has a significant influence on the SIF. Fig. 9 gives contour plots of the frictional stress for the three bearing ratios and for a relative crack length of $a / w=0.1$. The load is applied to the bottom far field (related to the figure orientation, indicated with an arrow). For a low applied load $(\beta=0.3)$ the largest frictional stress is obtained at the bottom side of the figure, i.e. before the load passes the crack, due to the larger relative displacement of the cracked plate. This effectively reduces the SIF. The opposite is valid for high applied loads $(\beta=0.7)$, where the largest frictional stress develops at the top side of the figure, determining that a larger portion of the load contributes to opening the crack tip because of the prying effect. Consequently, the frictional force has insignificant influence on the SIF for such a high bearing ratio. Indeed, Fig. 8b indicates that the results for $\beta=0.7$ are close to the results for $\beta=1$.

Based on an analytical (two-dimensional) derivation, Cartwright and Parker [47] provide tabulated values for the SIF for bypass loading and for internal hole pressure. Superposition of these two cases provides tabulated values for pin loading. The dashed curves in Fig. 8a represent the resulting geometrical correction factors. The analytical equations agree well with the results of the three-dimensional model. By combining these analytically derived solutions, an approximate prediction is derived for the geometrical correction factor in case friction and clamping are present. Similar to the SCF, a linear transition is assumed between pure friction at $\beta=0$ and pure bearing at $\beta=1$ :

$Y=\beta Y_{\text {pin }}+(1-\beta) Y_{\text {fric }}$

where $Y_{\text {fric }}=0.5 Y_{\text {bear }}$ for low $\beta$ values and $Y_{\text {fric }}=Y_{\text {pin }}$ for high $\beta$ values and a linear transition is assumed in between. A good fit of the numerical results is obtained if a perfect cone is assumed for $\beta \leq 0.2$ and pure pin loading for $\beta>0.8$ :

$Y_{\text {fric }}=\left\{\begin{array}{cc}0.5 Y_{\text {byp }} & \beta \leq 0.2 \\ \left(\frac{5}{6} \beta-\frac{1}{3}\right) Y_{\text {pin }}+\left(-\frac{5}{6} \beta+\frac{2}{3}\right) Y_{\text {byp }} & 0.2<\beta<0.8 \\ Y_{\text {pin }} & \beta \geq 0.8\end{array}\right.$

Combining Eqs. (24) and (25) and using the tabulated values for $Y_{\text {byp }}$ and $Y_{\text {pin }}$ in [47] gives the dashed curves in Fig. 8b and c. The figures demonstrate the reasonable agreement between Eqs. (24) and (25) and the result of the FE analyses, even though the two geometries 

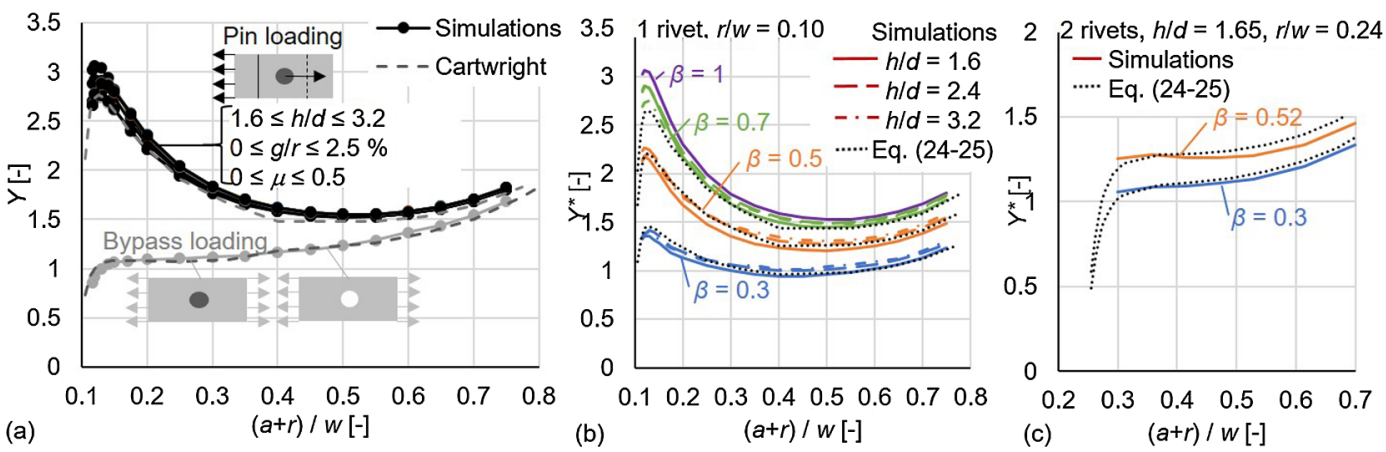

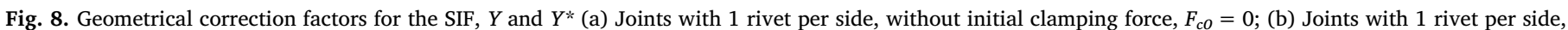
with $\sigma_{c o}=100 \mathrm{MPa}$ and $\mu=0.5$; (c) Joints with 2 rivets per side, with $\sigma_{c o}=100 \mathrm{MPa}$ and $\mu=0.5$.

of Fig. $8 \mathrm{~b}$ and $\mathrm{c}$ and hence the geometric correction factors $\mathrm{Y*}$ values are completely different.

Fig. 10 presents the results for cyclic loading for the single rivet geometry, with a maximum applied load exceeding the slip resistance. The SIF does not return to its original value after unloading, Fig. 10a, because of the remaining frictional force. Fig. 10b provides the bearing and friction forces for a certain geometry, where the bearing and friction forces are extracted from the contact between rivet and central plate and contact between central and cover plates, respectively. First loading (1) gives a nonlinear relation between applied load and bearing or frictional forces. The frictional force reduces due to lateral contraction at the onset of slip. When unloaded (2), a frictional strength develops in opposite direction and the stress state at zero load deviates from the initial stress state. The maximum SIF of the first semi cycle is again obtained when reloaded (3). The results of different simulations with varying bearing ratio and crack size, Fig. $10 \mathrm{c}$, indicate that the ratio between the range of the SIF of the cyclic load and that of the first semi cycle is almost independent of the crack size and that it does depend on the bearing ratio. The cyclic range of the SIF is thus much lower than the monotonic value, especially for low bearing ratios. The effective SIF ratio $\left(R=K_{\min } / K_{\max }\right)$ is in this case with full unloading $\left(F_{\min }=0\right)$ equal to $R=1-\Delta K_{2} / \Delta K_{1}$ and consequently, a low bearing ratio implies a high effective SIF ratio. This is also visible in Fig. 10d, which presents the average values of both ratios for all crack sizes.

\section{Results and discussion}

Fatigue tests on hot riveted double covered butt joints either with one rivet or with two rows of one rivet per joint side are reported in $[10,50-54]$. Different geometries and load conditions have been applied in each test series. Table 2 provides the test results. Columns 3-8 provide the material applied, the geometric properties, and the (average) stress ratio of the applied load, $R_{a p p}$. Column 9 gives the number of tests per series, $n$. Only failed specimens are counted because, the number of runouts is not provided in all sources. Some test series consist of a sufficient number of tests allowing for a reasonable estimate of the characteristic fatigue strength, but most series consist of maximum 4 tests only. This complicates the evaluation of the test series and hence the factors that determine the fatigue strength, because larger sampling uncertainty affects the statistical evaluation of the data. Fig. 11 gives the results of all 156 individual failed test. The figure demonstrates the large scatter resulting if all double covered butt joints are grouped into a single characteristic fatigue strength.

The fatigue life prediction model of Section 2 (Fig. 1) is applied to predict the fatigue life of each test series. The initial clamping stress in the rivets is an important source of variability in the fatigue life. The clamping stress depends on many aspects such as the hammering method, hammering time, rivet temperature, rivet head, and rivet length compared to plate assembly thickness, [56]. A limited number of test series aiming at determining the clamping stress is described in literature where the number of tests is sufficient for reasonable estimators of the mean and standard deviation of the clamping stress. Zhou [57] measured the clamping stress in rivets after assembly. The measured values ranged between 24 and $165 \mathrm{MPa}$ with an average value of $83 \mathrm{MPa}$. The thickness of the plate assembly, $h$, is not provided but, given the type of joint considered (angles to a web plate), it is probably close to the thicknesses of the test series in Table 2. Larger clamping stresses ranging between 110 and $189 \mathrm{MPa}$ with an average value of $151 \mathrm{MPa}$ were measured in [58] for $h=30 \mathrm{~mm}$, but this is based on 6 tests only. Significantly larger clamping stresses were reported in [6] for large values of $h$. The data of $[57,6]$ is in line with [5], where a graph is provided that shows an increasing average and reducing
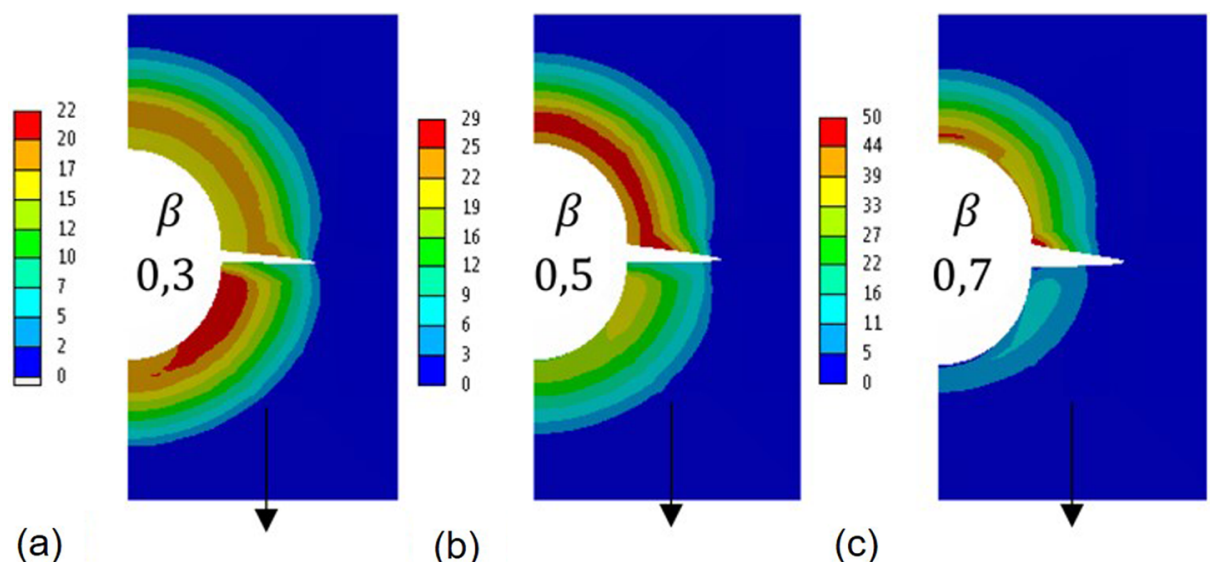

(c)

Fig. 9. Friction stress in MPa between the central plate and the cover plate for the case of Fig. $8 \mathrm{~b}$ with $a=r=0.1 w$ and for different bearing ratios: (a) $\beta=0.3$; (b) $\beta=0.5$; (c) $\beta=0.7$. 

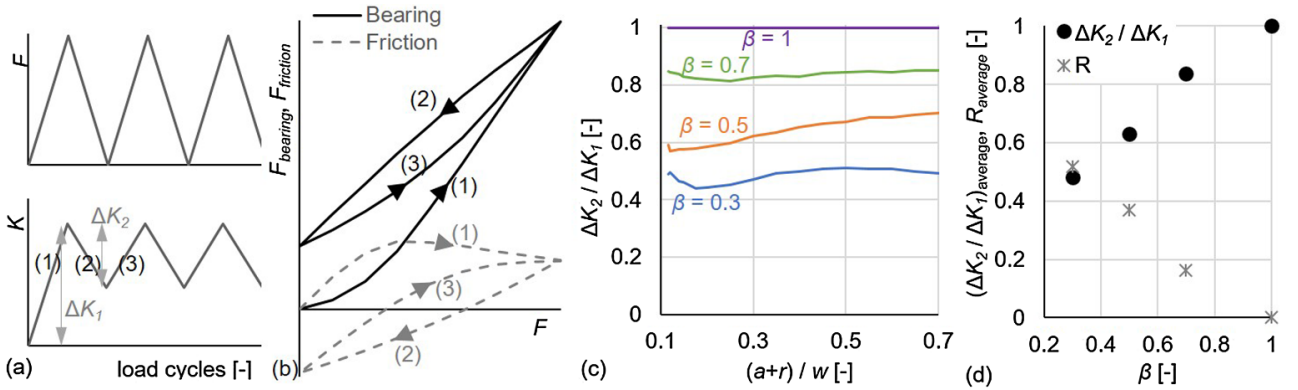

Fig. 10. Stress intensity factors for cyclic loading with a load exceeding the slip strength: (a) Principle of a remaining SIF after the first semi cycle; (b) Bearing and friction forces; (c) Ratio between SIF of the cyclic load and SIF of the first semi cycle for $r / w=0.1$, $h / d=1.6, \quad \mu=0.5, \quad \sigma_{c o}=100 \mathrm{MPa} ; \quad(\mathrm{d})$ Average SIF ratio and stress ratio as a function of bearing stress for the same case. standard deviation of the clamping stress with increasing $h$. The initial clamping stress is assumed at $100 \mathrm{MPa}$ in the prediction model in the current research but the simulations of two test series were repeated with a lower clamping stress to determine the sensitivity. The friction coefficient was taken as 0.33 or 0.06 - representing friction tests of specimens with mill scale or red lead, respectively, in [2].

In most of the tests on which the correlation in [36] between the Brinell hardness and the fatigue strength variables $e_{f}^{\prime}$ and $s_{f}^{\prime}$ are based (Table 1), crack initiation was related to a deviation in the measured strain. In our experience, this takes place at a crack size of a few tenths of millimetres. Hence, the crack propagation model is applied starting from a (still somewhat arbitrary) crack size of $a_{O}=0.3 \mathrm{~mm}$. The final crack size considered is $a_{\text {fin }}=0.8(w+r)$, which is the largest size for which SIF values are provided in [47]. Using the approximate relations of Eqs. (21), (24) and (25), the prediction model of Section 2 provides a fatigue propagation life that comprises a small fraction of the total life. The propagation life is more important for very large applied stress ranges - in line with the simulations in [25] - but the simulated propagation life comprises not more than $5 \%$ of the total life for the majority of the tests. A short propagation life agrees with observations from tests for a different type of riveted joint in [55] and it is confirmed by the author of [7] for riveted joints in general (personal

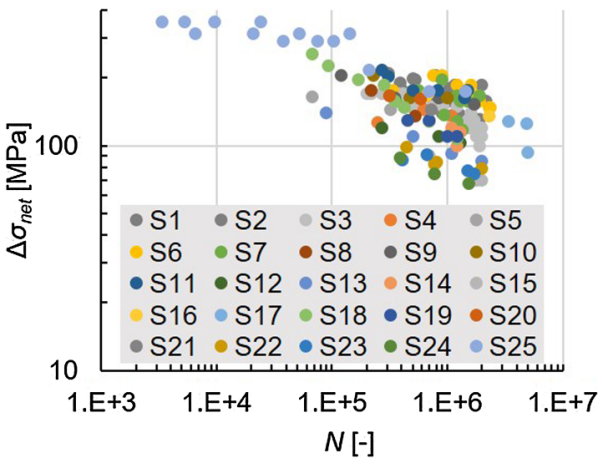

Fig. 11. Results of all failed tests on hot riveted double covered butt joints.

communication with author). For this reason, in simulating the results of each test series, the SIF values applied in the crack propagation model (right hand side of Fig. 1) were estimated using Eqs. (24) and (25), instead of determining them from a FE model of that specific geometry. On the contrary, FE models were developed for each geometry and each combination of applied stress range and stress ratio to determine the theoretical notch stresses and predict the number of

Table 2

Tests and prediction results.

\begin{tabular}{|c|c|c|c|c|c|c|c|c|c|c|}
\hline Series & Source & No. rivets & Surface finish & Steel grade & $r / w$ & $t / w$ & $R_{a p p}$ & No. tests & $\frac{\Delta \sigma_{\text {model }}^{*}}{\Delta \sigma_{\text {tests }}^{*}}$ & $\Delta \sigma_{2 E 6}[\mathrm{MPa}]$ \\
\hline S1 & [50] & 2 & Mill scale & St37 & 0.24 & 0.17 & $0.11^{\mathrm{a}}$ & 18 & 0.97 & 138 \\
\hline S2 & [50] & 2 & Mill scale & St37 & 0.24 & 0.17 & $0.22^{\mathrm{a}}$ & 8 & 0.89 & 128 \\
\hline S3 & c & 2 & Mill scale & St37 & 0.20 & 0.13 & 0.00 & 25 & 1.03 & 125 \\
\hline S4 & [51] & 2 & Mill scale & St37 & 0.19 & 0.14 & 0.20 & 3 & 0.99 & 110 \\
\hline S5 & [51] & 2 & Mill scale & St37 & 0.17 & 0.12 & 0.20 & 3 & 0.98 & 110 \\
\hline S6 & [50] & 2 & Mill scale & St52 & 0.24 & 0.17 & $0.10^{\mathrm{a}}$ & 14 & 0.93 & 148 \\
\hline S7 & [50] & 2 & Mill scale & St52 & 0.24 & 0.17 & $0.31^{\mathrm{a}}$ & 12 & 0.95 & 130 \\
\hline S8 & [52] & 2 & Mill scale & St52 & 0.16 & 0.08 & $0.03^{\mathrm{a}}$ & 2 & 1.05 & 128 \\
\hline S9 & [52] & 2 & Mill scale & St52 & 0.21 & 0.10 & $0.03^{\mathrm{a}}$ & 4 & 1.08 & 157 \\
\hline S10 & [52] & 2 & Mill scale & St52 & 0.21 & 0.16 & $0.03^{\mathrm{a}}$ & 5 & 1.00 & 148 \\
\hline S11 & [52] & 2 & Mill scale & St52 & 0.25 & 0.22 & $0.03^{\mathrm{a}}$ & 7 & 1.03 & 162 \\
\hline S12 & [52] & 2 & Mill scale & St52 & 0.21 & 0.10 & 0.67 & 3 & 1.13 & 112 \\
\hline S13 & [52] & 2 & Mill scale & St52 & 0.21 & 0.14 & 0.67 & 4 & 1.17 & 104 \\
\hline S14 & [52] & 2 & Mill scale & St52 & 0.25 & 0.22 & 0.67 & 3 & 1.10 & 115 \\
\hline S15 & [52] & 2 & Mill scale & St52 & 0.21 & 0.14 & 0.81 & 3 & 1.16 & 81 \\
\hline S16 & c & 2 & Red lead & St37 & 0.25 & 0.15 & 0.00 & 2 & 0.95 & 133 \\
\hline S17 & {$[53]^{d}$} & 2 & Red lead & St37 & 0.36 & 0.15 & 0.14 & 3 & 1.12 & 140 \\
\hline S18 & {$[50]$} & 2 & Red lead & St52 & 0.24 & 0.17 & $0.11^{\mathrm{a}}$ & 8 & 1.11 & 133 \\
\hline S19 & [52] & 2 & Red lead & St52 & 0.24 & 0.17 & $0.14^{\mathrm{a}}$ & 4 & 1.29 & 132 \\
\hline S20 & [54] & 1 & Mill scale & St37 & 0.29 & 0.20 & 0.00 & 2 & 0.92 & 128 \\
\hline S21 & [54] & 1 & Mill scale & St37 & 0.29 & 0.23 & 0.00 & 1 & 0.95 & 125 \\
\hline S22 & [54] & 1 & Mill scale & St37 & 0.29 & 0.17 & 0.67 & 4 & 1.18 & 89 \\
\hline S23 & [54] & 1 & Mill scale & St37 & 0.29 & 0.20 & 0.67 & 4 & 1.12 & 82 \\
\hline S24 & [54] & 1 & Mill scale & St37 & 0.29 & 0.23 & 0.67 & 3 & 1.28 & 83 \\
\hline S25 & [10] & 1 & Mill scale & Puddle iron & 0.53 & 0.33 & 0 & 14 & 1.01 & $201^{b}$ \\
\hline
\end{tabular}

\footnotetext{
a Tests were carried out with a constant minimum stress. The stress ratio is the average of the tests.

b Simulation with St37 gives $\Delta \sigma_{2 E 6}=247 \mathrm{MPa}$.

c Undocumented test series. See the Annex for geometry and test data.

d Data is also presented in [3].
} 


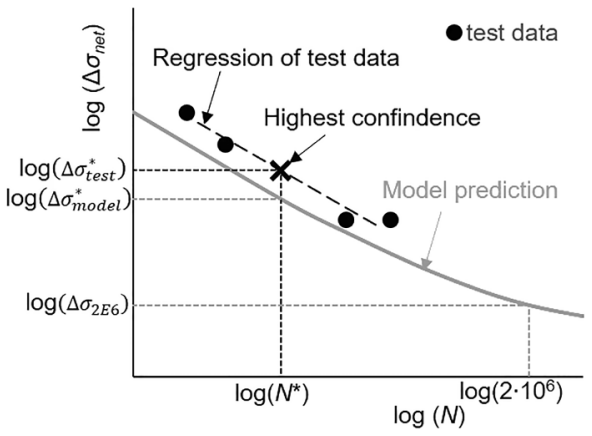

Fig. 12. Explanation of symbols $\Delta \sigma_{\text {tests }}^{*}, \Delta \sigma_{\text {model }}^{*}, \Delta \sigma_{2 E 6}$, and $N^{*}$.

cycles to crack initiation (left hand side of Fig. 1).

Considering a logarithmic relation between the stress range and the number of cycles, the net section stress range representing the centroid of a test series, $\Delta \sigma_{\text {test }}^{*}$, and the corresponding number of cycles, $N^{*}$, are obtained from:

$\log \left(\Delta \sigma_{\text {test }}^{*}\right)=\frac{1}{n} \sum_{i=1}^{n} \log \left(\Delta \sigma_{i}\right)$

$\log \left(N^{*}\right)=\frac{1}{n} \sum_{i=1}^{n} \log \left(N_{i}\right)$

The uncertainty of the fatigue strength (or fatigue life) evaluated from the tests is the smallest at the centroid. The net section stress range $\Delta \sigma_{\text {model }}^{*}$ is obtained from the prediction model at the number of cycles $N^{*}$. The ratio $\Delta \sigma_{\text {model }}^{*} / \Delta \sigma_{\text {tests }}^{*}$ is thus an indication of the agreement between tests and model. The symbols $\Delta \sigma_{\text {tests }}^{*}, \Delta \sigma_{\text {model }}^{*}$ and $N^{*}$ are visualised in Fig. 12 and the ratio is given in column 10 of Table 2. The agreement is good or very good for most test series, with $0.89 \leq \Delta \sigma_{\text {model }}^{*} / \Delta \sigma_{\text {tests }}^{*} \leq 1.11$ and this includes all series with more than 4 samples. The average ratio weighted by the number of tests is equal to $\Delta \sigma_{\text {model }}^{*} / \Delta \sigma_{\text {tests }}^{*}=1.04$. Note that no model parameters were calibrated with riveted test results; the material variables of Section 2 were fitted on independent, plain parent material tests carried out by others and the clamping stress was fitted to experimental results. The ratio exceeds 1.11 for some series, but the confidence level of these series is low due to the very small number of tests. The model prediction is within the $50 \%$ 2-sided confidence level (25\% 1-sided confidence level) of the mean for all test series. As the value of the clamping stress is relatively uncertain, the simulations of test series S1 and S18 are repeated with a factor two lower initial clamping stress, i.e. $\Delta \sigma_{c 0}=50 \mathrm{MPa}$, to determine the sensitivity of the prediction to the clamping stress. The predicted fatigue strength reduces with $6 \%$ for series S1 (with mill scale) and with $2 \%$ for series S18 (red lead) as compared to the reference case with $\Delta \sigma_{c o}=100 \mathrm{MPa}$.

The last column of Table 2 provides the fatigue reference strength, $\Delta \sigma_{2 E 6}$, defined as the net section stress range predicted with the model at 2 million cycles to failure, see Fig. 12. A large difference in strength is observed between the different series, $81 \mathrm{MPa} \leq \Delta \sigma_{2 E 6} \leq 201 \mathrm{MPa}$, demonstrating that the strength depends heavily on the joint geometry and the applied stress ratio, which is a reasonable explanation for the large scatter in Fig. 11. The regression line of the test data in Fig. 12 is described with:

$N=C \cdot \Delta \sigma^{m}$

where parameters $C$ and $m$ are determined from the test data $\left(\Delta \sigma_{i}, N_{i}\right)$ using the least squares method. The standard deviation of $\log (C)$ is evaluated from the test series with $n \geq 10$ and the average weighted by the number of tests is equal to 0.32 . If we assume that this standard deviation is representative for all test series, the $5 \%$ fraction of the fatigue strength ranges between $65 \mathrm{MPa} \leq \Delta \sigma_{2 E 6 ; 5 \%} \leq 176 \mathrm{MPa}$. Hence, it is not justified that guidelines such as $[3,13,15]$ give a single fatigue

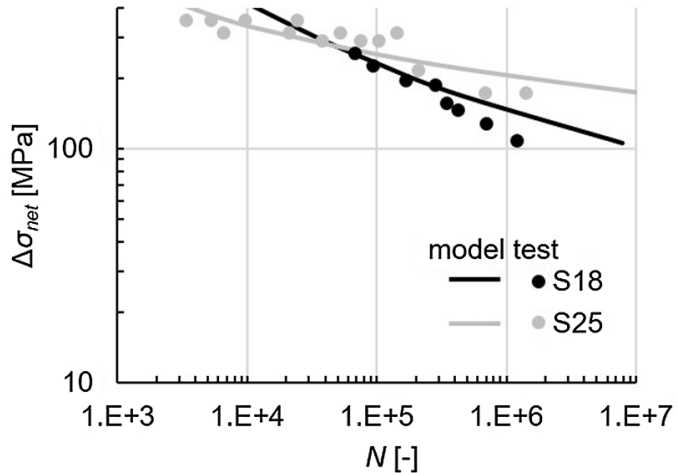

Fig. 13. Test results and model predictions of series with a wide range of $\Delta \sigma$.

strength for riveted (double covered) shear joints independent of the geometry and sometimes independent of the stress ratio.

The predicted slopes of the simulations agree well with the tests, see Fig. 13 for the comparison with the series with the largest net section stress range $\Delta \sigma_{i}$. The high SCF of riveted joints causes the slope parameter $m$ of Eq. (28) to be (much) larger than slope parameter $1 / b$ of the parent metal (Section 2). The slope parameter $m$ of the predicted S-N curve is not constant but it depends on the test series, which is a result of the dependency between SCF and $r / w$ ratio as demonstrated in Fig. 5 and of the material grade. The slope parameter decreases for decreasing stress range, giving a shallower S-N curve at small stress ranges as compared to large stress ranges. This is attributed to the decreasing SCF for decreasing stress as demonstrated in Fig. 6a. The slope parameter ranges between $-9 \leq m \leq-5$ for cycle numbers $10^{5} \leq N \leq 5 \cdot 10^{6}$, whereas $1 / b=-11$. Based on the evaluation of test results of a different type of riveted joint, [7] recommends an abrupt slope change from $m=-3$ to $m=-5$ for riveted joints at $N=7 \cdot 10^{5}$ cycles, whereas [3] recommended this slope change at $N=1.5 \cdot 10^{6}$ cycles. This research shows that the slope change is more gradual. The slope parameter $m=-10$ as advised in [18] is applicable only for the material type, $r / w$ ratio, and applied stress ratio used in that research.

The advantage of the prediction model is that it enables to determine the contribution of a single parameter on the fatigue strength. It is applied here to determine the influence on the fatigue resistance of the steel grade, the surface finish, the stress ratio, the relative plate thickness, and the relative plate width, with results discussed hereafter. Fig. 14 gives the results of tests and of model predictions of the same geometries and stress ratios, but different material properties. Both tests and prediction indicate that the difference between the steel grades St37 and St52 as applied for the plate material is marginal. A simulation using the same geometry but with puddle iron shows a significantly

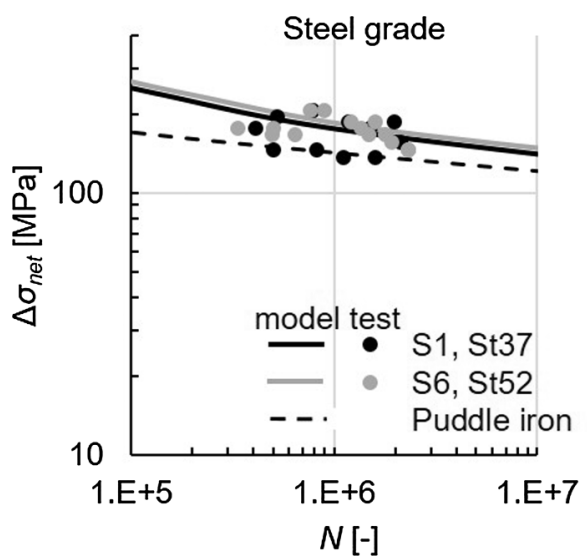

Fig. 14. Test results and model predictions for different steel grades (series S1 excluding test data on Thomas steel). 

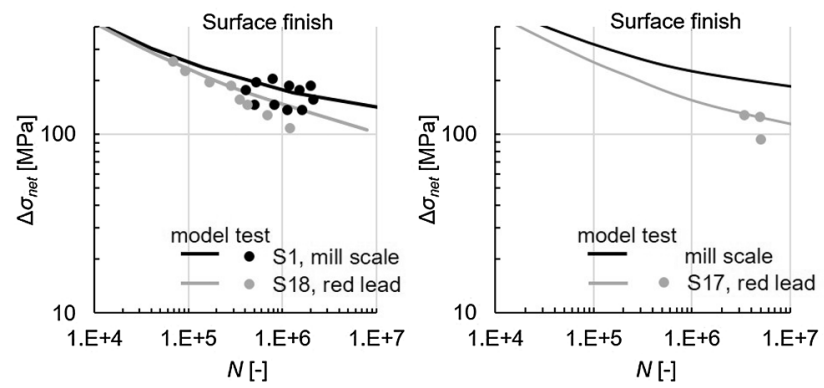

Fig. 15. Test results and model predictions for different surface finish (series S1 excluding test data on Thomas steel).

lower fatigue strength as compared to the steel grades. This difference between metals is in line with [12], but the fatigue strength obtained in this research is significantly lower as compared to [12] for both metal groups.

Fig. 15 provides the test results and model predictions of tests with the same geometry and applied stress ratio but different surface conditions. The simulations with red lead paint are carried out with a friction coefficient $\mu=0.3$ between the rivet and the plates and $\mu=0.06$ between the plates. The surface finish has limited influence on the fatigue strength at relatively high stress ranges, which is attributed to the dominance of load transfer by pin loading. At relatively low stress ranges, however, the read lead tests and model predictions have a significantly lower fatigue strength as compared to the mill scale condition. Taras and Greiner [7] recommend a lower fatigue strength if read lead is applied on specimens of St52. The results of the model suggest that the reduction of the fatigue strength in presence of red lead paint applies to all materials and determines a large difference in the fatigue life at relatively low stress ranges.

Fig. 16 demonstrates that the applied stress ratio, $R_{a p p}$, has a significant influence on the fatigue strength of hot riveted double covered butt joints. By comparing the prediction and the test data, it results that the model consistently overpredicts the fatigue strength of the tests with a high stress ratio $R_{a p p} \geq 0.67$. It is possible that the Morrow correction is inaccurate for high stress ratios. In order to investigate this, the predictions are repeated with the Smith-Watson-Topper (SWT) model [59], which replaces Eq. (1) with:

$e_{a} S_{\max }=\frac{s_{f}^{\prime 2}}{E}\left(2 N_{i}\right)^{2 b^{\prime}}+\dot{e}_{f}^{\prime} S_{f}^{\prime}\left(2 N_{i}\right)^{b^{\prime}+c}$

The SWT model provides a weighted average ratio between tested and predicted fatigue strength of $\Delta \sigma_{\text {model }}^{*} / \Delta \sigma_{\text {tests }}^{*}=0.90$, against the 1.04 resulting by the use of the Morrow mean stress correction. The SWT model provides a more consistent agreement with the tests concerning the influence of the stress ratio on the fatigue strength. However, it should be noted that the test series with large deviation between $\Delta \sigma_{\text {tests }}^{*}$ and $\Delta \sigma_{\text {model }}^{*}$ using the Morrow mean stress correction, contain maximum
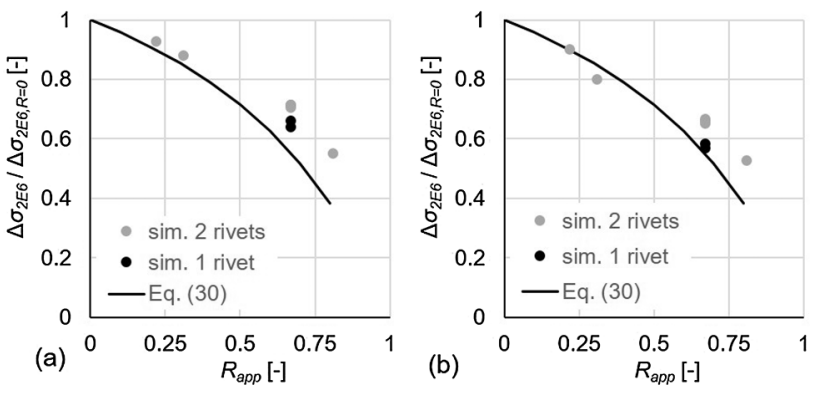

Fig. 17. Reduction factor for the fatigue strength for a given applied stress ratio, $R_{\text {app }}$, compared to $R_{\text {app }}=0$, according to Eq. (30) (curve) and the model predictions (dots) with: (a) mean stress correction according to Morrow [29]; (b) the SWT model [59].

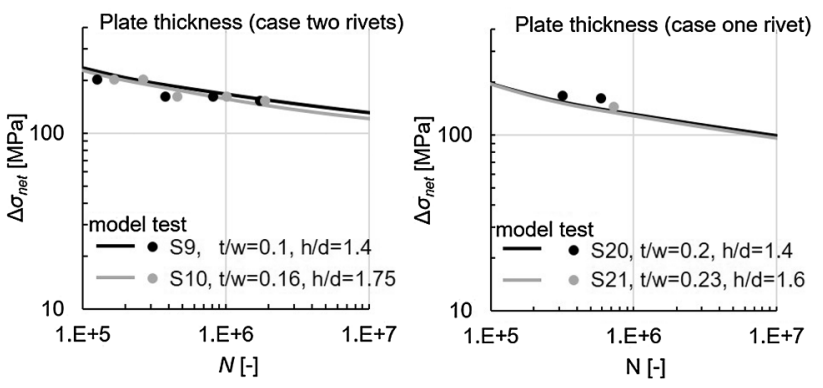

Fig. 18. Test results and model predictions for different plate thickness, presented as plate thickness over with ratio and rivet diameter over length ratio.

4 failed specimens only. In addition, some of these series contain runouts at the same stress ranges as the failed data, so that the actual average fatigue strength is larger than suggested by the value $\Delta \sigma_{\text {tests }}^{*}$. However, independently of the degree of accuracy of the model, the test data plot in Fig. 16 suggests that a fatigue strength value independent of the stress ratio, as applied in $[13,15]$ for shear hot riveted joints, is not justified. Taras and Greiner [7] suggest the following dependency between the fatigue strength and the applied stress ratio:

$\frac{\Delta \sigma_{2 E 6}}{\Delta \sigma_{2 E 6 ; R=0}}=\frac{1-R_{a p p}}{1-0.6 R_{a p p}}$

where $\Delta \sigma_{2 E 6 ; R=0}$ is the fatigue strength at 2 million cycles at applied stress ratio $R_{a p p}=0$. Fig. 17 provides this relationship together with the model predictions. For $R_{\text {app }}>0$, Eq. (30) determines a more conservative mean stress correction than the simulations but is closer to the prediction obtained using the SWT model than the Morrow correction.

The relative plate thickness can be presented as the central plate thickness over width ratio $(t / w)$ or as the rivet shaft height over diameter ratio $(h / d)$. The latter parameter also comprises the thickness of the cover plates. Fig. 18 presents both ratios and shows that the plate
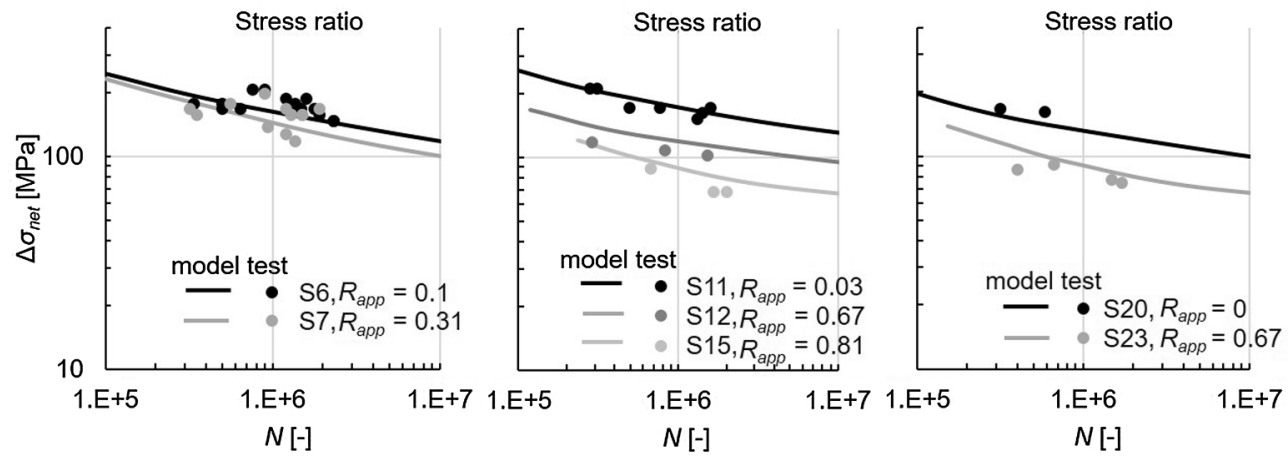

Fig. 16. Test results and model predictions for different applied stress ratios. 

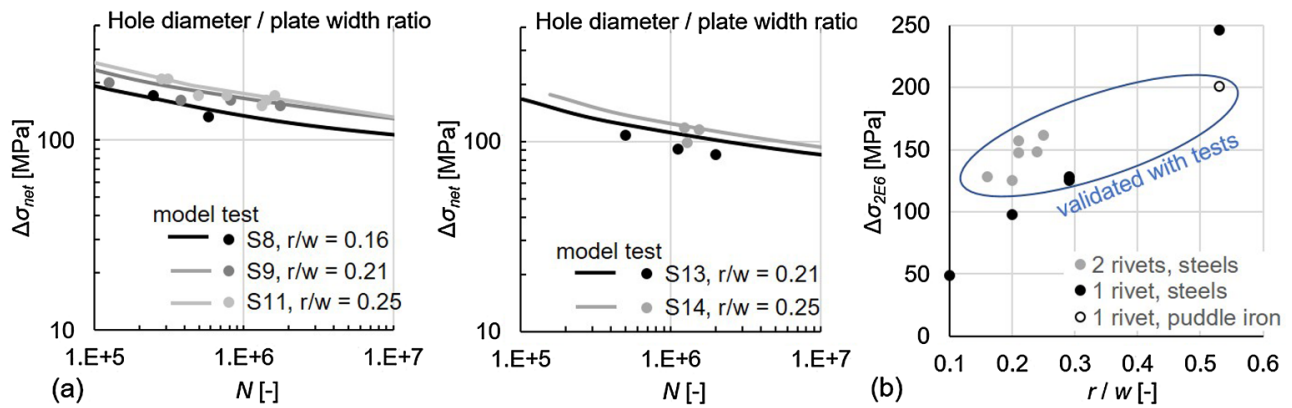

Fig. 19. Test results and model predictions for different rivet diameter over plate width ratios: (a) Individual series; (b) Average fatigue strength for mill scale surface finish and $0<R_{\text {app }} \leq 0.1$.

thickness has a limited influence on the fatigue strength. However, it should be noted that the fatigue failure mode considered in this research is evaluated for the central plate. Tests carried out by Graf $[52,54]$ show that fatigue of the rivet may be decisive for large plate thickness.

Fig. 19 demonstrates that the rivet diameter over plate width ratio is a crucial parameter for the fatigue strength. The smaller $r / w$, the larger is the SCF for pin loading, see Fig. 5, and hence the lower is the fatigue strength. The large $r / w$ ratio applied in [10] gives a high fatigue strength. The strength predicted with the same geometry but with mild steel would be as high as $247 \mathrm{MPa}$. Such a very high strength applies to very high $r / w$ ratios only. The $5 \%$ fraction of the fatigue strength at 2 million cycles provided in [7] is $\Delta \sigma_{2 E 6,5 \%}=90 \mathrm{MPa}$ if the ratio between the theoretical bearing stress and the net section stress is smaller than 2, whereas it is $\Delta \sigma_{2 E 6,5 \%}=80 \mathrm{MPa}$ if this condition is not satisfied. The current research demonstrates that this division is too simplified. Instead, a continuous and much larger dependency between $r / w$ and $\Delta \sigma_{2 E 6}$ is observed from tests and model, see Fig. 19. The recommended $5 \%$ fraction of the strength in [12] and in [18] at $R_{a p p}=0$, which give $\Delta \sigma_{2 E 6,5 \%}=122 \mathrm{MPa}$ and $\Delta \sigma_{2 E 6,5 \%}=107 \mathrm{MPa}$, respectively, only applies to a limited number of geometries and may be too optimistic - i.e. unconservative - for many practical cases.

The agreement between tests and model prediction indicates that the model can be applied for the simple geometries considered here. In case of larger joints with more rivets, the variability of clamping forces within a riveted joint may not only affect the scatter in fatigue strength but also the average fatigue strength. On the one hand, the rivet with the lowest clamping force may induce failure of the joint because of the weakest link principle. On the other hand, a full crack between two rivet holes may not yet result into failure of the entire joint. Monte Carlo simulations with random clamping force per rivet may be applied in such a case to estimate the fatigue strength, as shown in [27].

\section{Conclusions}

A two-stage fatigue strength prediction model for hot riveted double covered butt joints is presented, which uses the Basquin-Coffin-Manson strain-life curve with mean stress correction according to Morrow for crack initiation and fracture mechanics for fatigue crack growth. The notch stresses and the SIFs used in the model are obtained from finite element (FE) models that include measured values for rivet clamping and friction between plates and between plate and rivets. No specific calibration of factors for riveted joints is involved. The model prediction agrees well with results from tests: the predicted fatigue strength is on average $4 \%$ higher as compared to the results of 25 test series including a total of 156 failed samples. The prediction is within the $50 \%$ confidence interval of the mean response for each individual test series.

The model also gives insights into the load transfer mechanism between the parts. As the applied load increases, a larger portion of it is transferred through bearing, creating a relatively large stress concentration. This determines that the slope of the S-N curve changes with the applied stress and that the ratio between the theoretical maximum stress at the notch root and applied stress, i.e. the stress concentration factor, is dependent on the applied load. Local slip between the plates already occurs at relatively low applied load levels and this causes that the contact stresses do not return to original values after unloading. Hence, both loading and unloading must be simulated in the FE model and this causes a significant influence of the applied stress ratio on the fatigue strength.

Fatigue crack initiation appears to be relatively important for these types of joint, the crack propagation life is in most cases less than $5 \%$ of the total life. The combination of fatigue test data and the model prediction provides a good basis for predicting the fatigue strength and quantifying the contribution of individual parameters to the fatigue strength. The $5 \%$ fraction of the fatigue strength ranges between $65 \mathrm{MPa}$ and $176 \mathrm{MPa}$ for the geometries and stress ratios involved. This indicates that a single detail category for all hot riveted double covered butt joints, as provided in guidelines, is inappropriate. The fatigue strength is found to be most sensitive to the applied stress ratio and the rivet diameter to plate width ratio, the latter parameter being responsible for the bearing stress. Joints of puddle iron have a significantly lower fatigue strength than those made of steel, but the difference between St37 and St52 steel grades is found to be not important. The surface finish of the plates - mill scale or red lead paint between the plates - is found to affect the fatigue life especially at relatively low stress ranges, where a significant part of the load is transferred by frictional forces. The plate thickness has a minor influence on the fatigue strength if failure of the rivet itself is excluded. The fatigue strength of hot riveted joints in guidelines should be updated based on these findings.

\section{Annex. Test data not reported elsewhere}

The authors found two sources containing test data of riveted joints with geometries according to Fig. 2 and that have not been reported elsewhere.

Series S3 in Table 2 is reported by the Rumanian railway authority CRF (year unknown). Plate material is St37, rivet material is St34. The tests were carried out with non-treated plate surfaces (i.e. mill scale). The geometry is according to the right hand side of Fig. 2 with the following dimensions: $2 t=15 \mathrm{~mm}, t_{c}=10 \mathrm{~mm}, h=35 \mathrm{~mm}, 2 w=115 \mathrm{~mm}, r=11.5 \mathrm{~mm}, d=23 \mathrm{~mm}, l=45 \mathrm{~mm}, l_{1}=45 \mathrm{~mm}, l_{2}=80 \mathrm{~mm}$. Test data (failure or runout at given number of cycles for net section stress range) are obtained from a digitized graph and are provided in Table 3.

Series S16 in Table 2 is reported by the centre of technical research CTO of the Dutch railway authority NS (year unknown).

Plate material is St37, rivet material is St34. The tests were carried out with red lead on the plate surfaces. The geometry is according to the right 
Table 3

Fatigue test data of Series S3.

\begin{tabular}{llll}
\hline Failed tests & & Runouts & \\
\hline$\Delta \sigma$ & $N$ & $\Delta \sigma$ & $N$ at end of test \\
\hline 170 & $2.0 \cdot 10^{5}$ & 130 & $2.2 \cdot 10^{6}$ \\
170 & $2.2 \cdot 10^{5}$ & 120 & $2.3 \cdot 10^{6}$ \\
170 & $2.7 \cdot 10^{5}$ & 120 & $2.5 \cdot 10^{6}$ \\
170 & $3.2 \cdot 10^{5}$ & 110 & $2.2 \cdot 10^{6}$ \\
170 & $3.7 \cdot 10^{5}$ & 110 & $2.4 \cdot 10^{6}$ \\
170 & $4.2 \cdot 10^{5}$ & 100 & \\
150 & $4.2 \cdot 10^{5}$ & & \\
150 & $4.7 \cdot 10^{5}$ & & \\
150 & $5.3 \cdot 10^{5}$ & & \\
150 & $7.3 \cdot 10^{5}$ & & \\
150 & $9.2 \cdot 10^{5}$ & & \\
150 & $1.2 \cdot 10^{6}$ & & \\
140 & $1.6 \cdot 10^{6}$ & & \\
130 & $1.5 \cdot 10^{6}$ & & \\
130 & $1.6 \cdot 10^{6}$ & & \\
130 & $1.7 \cdot 10^{6}$ & & \\
120 & $1.5 \cdot 10^{6}$ & & \\
120 & $1.6 \cdot 10^{6}$ & & \\
120 & $1.7 \cdot 10^{6}$ & & \\
120 & $1.8 \cdot 10^{6}$ & & \\
120 & $1.9 \cdot 10^{6}$ & & \\
110 & $2.0 \cdot 10^{6}$ & & \\
110 & $1.8 \cdot 10^{6}$ & & \\
100 & $1.0 \cdot 10^{6}$ & $10^{6}$ & \\
\hline
\end{tabular}

Table 4

Fatigue test data of Series S16.

\begin{tabular}{llcc}
\hline Failed tests & & Runouts & $N$ at end of test \\
\hline$\Delta \sigma$ & $N$ & $\Delta \sigma$ & $1.0 \cdot 10^{7}$ \\
\hline 170 & $6.8 \cdot 10^{5}$ & 135 & \\
\hline
\end{tabular}

hand side of Fig. 2 with the following dimensions: $2 t=12 \mathrm{~mm}, t_{c}=10 \mathrm{~mm}, h=34 \mathrm{~mm}, 2 w=80 \mathrm{~mm}, r=10 \mathrm{~mm}, d=20 \mathrm{~mm}, l=50 \mathrm{~mm}$, $l_{1}=50 \mathrm{~mm}, l_{2}=100 \mathrm{~mm}$. Test data (failure or runout at given number of cycles for net section stress range) are provided in Table 4 .

\section{References}

[1] Collette Q, Wouters I, Lauriks L, et al. Riveted connections in historical iron and steel structures: one turbulent century of technological, structural and geometrical considerations (1840-1940). Matériaux \& Techniques 2012;100:137-54.

[2] Kulak GL, Fisher JW, Struik JHA. Guide to design criteria for bolted and riveted joints. Chicago: American Institute of Steel Constructions; 2001.

[3] ORE. Statistische Auswertung von Ermüdungsversuchen an Nietverbindungen in Flussstahl. Utrecht: ORE; 1986.

[4] Allan RN, Fisher JW. Bolted joints with oversized and slotted holes. J Struct Div ASCE 1968;4.

[5] Van Maarschalkerwaart HMCM. Fatigue behaviour of riveted joints. In: Proc 37th IABSE colloquium, Lausanne; 1982. p. 691-8.

[6] Baron F, Larson J. The effect of grip on the fatigue strength of riveted and bolted joints. Bull Am Rly Eng Ass 1952;54:175-90.

[7] Taras A, Greiner R. Development and application of a fatigue class catalogue for riveted bridge components. Struct Eng Int 2010;20:91-103.

[8] Al-Emrani M. Fatigue in riveted railway bridges Doctoral thesis Gothenburg, Sweden: Chalmers University of Technology; 2002

[9] Lesiuk G, Correia JAFO, Smolnicki M, et al. Fatigue crack growth rate of the long term operated puddle iron from the Eiffel bridge. Metals 2019;9:1-13.

[10] Sanches RF, de Jesus AMP, Correia JAFO, et al. A probabilistic fatigue approach for riveted joints using Monte Carlo simulation. J Constr Steel Res 2015;110:149-62.

[11] Meggiolaro MAÃ, Castro JTP. Statistical evaluation of strain-life fatigue crack initiation predictions. I J Fatigue 2004;26:463-76.

[12] UIC 70778-2. Recommendations for determining the carrying capacity and fatigue risks of existing metallic railway bridges. UIC; 2018.

[13] Kühn B, Lukic M, Nussbaumer A, et al. Assessment of existing steel structures: Recommendations for estimation of remaining fatigue life. JRC\&ECCS; 2008. Document available via < http://www.eurocodes.fi/1993/1993-1-9/background/ EUR23252EN.pdf $>$.
[14] Overbeeke JL, Alting TJ, Flipsen, et al. The fatigue strength of welded, bolted and riveted joints in high strength, low alloy steel. (EUT report. LSF, Laboratory for structural fatigue; Vol. THE-LSF-84-129). Eindhoven: Technische Hogeschool Eindhoven; 1984

[15] Sustainable bridges. Guideline for Load and Resistance Assessment of Existing European Railway Bridges. Cowi; 2007. Document available via < http://www. sustainablebridges.net/ $>$.

[16] Di Battista J, Adamson DEJ, Kulak GL. Fatigue strength of riveted connections. J Struct Eng 1998;124:792-7.

[17] Gallegos Mayorga L, Sire S, Correia JAFO, et al. Design S-N curves for old Portuguese and French riveted bridges connections based on statistical analyses. Proc Eng 2016;160:77-84.

[18] Pedrosa B, Correira JAFO, Rebelo C, et al. Fatigue resistance curves for single and double riveted joints from old portuguese metallic bridges. Eng Fail Anal 2019;96:255-73.

[19] Al Emrani M, Kliger R. FE analysis of stringer-to-floor beam connections in riveted railway bridges. J Constr Steel Res 2003;59:803-18.

[20] Correia JAFO, de Jesus AMP. Stress intensity factors evaluation for riveted beams applying FEA with VCCT. In: Bridge maintenance, safety and management. Pennsylvania, USA, 11-15 July 2010 .

[21] Imam BM, Righiniotis TD. Fatigue evaluation of riveted railway bridges through global and local analysis. J Constr Steel Res 2010;66:1411-21.

[22] Karunananda K, Ohga M, Dissanayake R, Siriwardane S. A combined high and low cycle fatigue model to estimate life of steel bridges. J Eng Tech Res 2010;2:144-60.

[23] Siriwardane S, Ohga M, Dissanayake R, Taniwaki K. Application of new damage indicator-based sequential law for remaining fatigue life estimation of railway bridges. J Constr Steel Res 2008;64:228-37.

[24] Marmo R. Numerical and experimental investigation on shear behavior of riveted connections Doctoral thesis Naples: University Federico II; 2011

[25] de Jesus AMP, Silva AL, Correia JAFO. Fatigue of riveted and bolted joints made of puddle iron - a numerical approach. J Constr Steel Res 2014;102:164-77.

[26] de Jesus AMP, Pinto H, Fernández-Canteli A, Castillo E, Correia JAFO. Fatigue 
assessment of a riveted shear splice based on a probabilistic model. Int J Fatigue 2010;32:453-62.

[27] Leonetti D, Maljaars J, Snijder HH. Fatigue life prediction of hot-riveted shear connections using system reliability. Eng Struct 2019;186:471-83.

[28] Manson SS. Fatigue: a complex subject - some simple approximations. Exp Mech $1965 ; 5: 193-226$.

[29] Morrow J. Fatigue properties of metals. In: Graham JA, Millan JF, Appl FJ, editors. Fatigue design handbook. SAE; 1968. p. 21-9.

[30] Ramberg W, Osgood WR. Description of stress-strain curves by three parameters. Technical note 902, NASA; 1943.

[31] Radaj D, Sonsino CM, Fricke W. Fatigue assessment of welded joints by local approaches. Woodhead Publishing; 2006.

[32] Mischke CR. Prediction of stochastic endurance strength. J Vib Acoust Stress Reliab Des 1987;109:113-22.

[33] Molski K, Glinka G. A method of elastic-plastic stress and strain calculation at a notch root. Mater Sci Eng 1981;50:93-100.

[34] Hänel B, Haibach E, Seeger T, et al. Analytical strength assessment of components made of steel, cast iron and aluminium materials in mechanical engineering. Frankfurt am Main: Forschungskuratoirium Maschinenbau - VDMA Verlag; 2012.

[35] Paris PC, Erdogan F. A critical analysis of crack propagation laws. J Basic Eng 1963;85:528-34.

[36] Roessle ML, Fatemi A. Strain-controlled fatigue properties of steels and some simple approximations. I J Fatigue 2000;22:495-511.

[37] Gallegos Mayorga L, Sire J, Correia JAFO. Statistical evaluation of fatigue strength of double shear riveted connections and crack growth rates of materials from old bridges. Eng Fract Mech 2017;185:241-57.

[38] BS 7910:2013 + A1:2015. Guide to methods for assessing the acceptability of flaws in metallic structures. London: BSI; 2015.

[39] Cremora C, Eichler B, Johansson B, et al. Sustainable bridges - background document D4.6. European Commission; 2007. Document available via $<$ http://www. sustainablebridges.net/ >

[40] de Jesus AMP, Maeiro JMC, da Silva ALL et al. Crack propagation behaviour of a puddle iron under constant and variable amplitude loading. In: Proc $8^{\circ}$ Congresso Nacional de Mecânica Experimental Guimarães; 2010. p. 1-10.

[41] da Silva ALL. Advanced methodologies for the fatigue analysis of representative details of metallic bridges PhD thesis Portugal: University of Porto; 2015
[42] Shih CF, Moran B, Nakamura T. Energy release rate along a three-dimensional crack front in a thermally stressed body. Int J Fracture 1986;30:79-102.

[43] Wilson WM, Thomas FP. Fatigue tests on riveted joints. Urbana: University of Illinois; 1938.

[44] Ansys. ANSYS Mechanical APDL structural analysis guide. ANSYS, Inc. 3304; 2012. p. 724-6.

[45] Pilkey DFP, Pilkey WD. Peterson's stress concentration factor. Wiley; 2008.

[46] Murakami Y. Stress intensity factors handbook. Pergamon Press; 1992.

[47] Cartwright DJ, Parker AP. Opening mode stress intensity factors for cracks in pinloads joints. Int J Fracture 1982;18:65-78.

[48] Chakherlou TN, Razavi MJ, Aghdam AB. On the variation of clamping force in bolted double lap joints subjected to longitudinal loading: a numerical and experimental investigation. Strain 2012;48:21-9.

[49] Farris TN, Murthy H, Matlik JF. Fretting fatigue. Comprehens Struct Integr 2003; 4:281-326.

[50] Klöppel K. Gemeinschaftversuche zur Bestimmung der Schwellzugfestigkeit voller, gelochter und genieteter Stäbe aus St37 und St52. Die Bautechnik 1936;13(14):96-112.

[51] Steinhardt O, Valtinat G. Versuche an Nietloch-Schweissverbindungen. Der Bauingenieur 1965;40:363.

[52] Graf O. Versuche im Stahlbau - Dauerversuche mit Nietverbindungen. Bericht des Anschusses für Versuche in Stahlbau 5. Berlin: Springer; 1935.

[53] NS Centrum voor Technisch Onderzoek, Report CTO/3/I/10.359/11,12,23. Nederlandse Spoorwegen, Utrecht (year unknown). (Data also available in ref. [3]).

[54] Graf O. Dauerversuche mit Nietverbindungen aus St37 zu erkunding des Einflusses von $\sigma: \tau$. Der Bauingenieur 1932;13:389-93.

[55] Al-Emrani M. Fatigue in riveted railway bridges PhD thesis Sweden: Chalmers; 2002

[56] Graf O. Versuche mit Nietverbindungen. Deutschen Anschlusses fur Stahlbau 1941;12:15-8.

[57] Zhou Y. Fatigue strength evaluation of riveted bridge members. Lehigh University; 1994.

[58] Akesson B. Fatigue life of riveted steel bridges. London, UK: Taylor and Francis; 2010.

[59] Smith KN, Watson P, Topper TH. A stress-strain function for the fatigue of materials. J Mater 1970;5:767-78. 